\title{
INFLUÊNCIA DA CONDUÇÃO DA DUPLA DESTILAÇÃO NAS CARACTERÍSTICAS FÍSICO-QUIMIICAS E SENSORIAIS DA AGUARDENTE DE CANA
}

\author{
LEANDRO CÉSAR BIZELLI
}

Engenheiro Agrônomo

Orientador: Prof. Dr. FERNANDO VALADARES NOVAES

Dissertação apresentada à Escola Superior de Agricultura "Luiz de Queiroz", Universidade de São Paulo, para a obtenção do título de Mestre em Ciências, Área de Concentração: Ciência e Tecnologia de Alimentos.

PIRACICABA

ESTADO DE SÃO PAULO - BRASIL

FEVEREIRO - 2000 


\title{
Dados Internacionais de Catalogação na Publicação (CIP) DIVISÃo DE BIBLIOTECA E DOCUMENTAÇÃO - Campus "Luiz de Queiroz"/USP
}

\author{
Bizelli, Leandro César \\ Influência da condução da dupla destilação nas caracteristicas físico-quimicas e \\ sensoriais da aguardente de cana / Leandro César Bizelli. - Piracicaba, 2000. \\ $61 \mathrm{p}$. \\ Dissertação (mestrado) - Escola Superior de Agricultura Luiz de Queiroz, 2000. \\ Bibliografia. \\ 1. Aguardente de cana-de-açúcar 2. Análise sensorial 3. Controle de qualidade 4. \\ Destilação 5. Propriedade fisico-química 6. Tecnologia de bebida 1. Título
}

CDD 663.53

"Permifida a cópia total ou parcial deste documento, desde que citada a fonte -0 autor" 
Dedico este trabalho aos meus pais, Sérgio e Janete e ao meu irmão Gustavo 


\section{AGRADECIMENTOS}

A todos que contribuíram para a realização deste trabalho, em especial:

- Ao Prof. Dr. Fernando Valadares Novaes, por me conceder a oportunidade, pela dedicação e atenção dispensadas;

- Ao Mestre e amigo Carlos Alberto França Ribeiro "Carlão", pela hospitalidade, pela amizade, pelo apoio e dedicação na elaboração da presente dissertação;

- Ao Prof. Dr. Jorge Horii;

- Ao Prof. Dr. Marco Antonio Azeredo Cesar;

- Ao Prof. Dr. Roberto Bovi;

- A Ariovaldo Faustino Soares da Silva, Nazareno Travagline Jr., Gustavo

S. Hildebrandt, Beatriz Mastrodi, Antonio Sampaio Baptista e André Sesso 
- A Sylvino Torrezan, Luiz Carlos Rodrigues "Melodia" e Rubens César Pereira;

- A Gislaine Nóbilo, Regina. Loureiro, Regina Gonçalves, Rosemary Mandro, Beatriz Giondo e Maria Joana Santos;

- A Constante Christofoletti, Eduardo Arthuso, Pedro Dorival Lucentini, Pedro Rossini Filho, Wilson Januário, Benedito Araújo e Noel Gonçalves;

- Ao CNPq, pelo auxílio concedido na forma de Bolsa de Estudos;

- Aos Engenheiros da SABESP Gerhson Mazzoni Negrão, Othon Xavier Biagionni Filho e Paulo de Tarso Pizza;

- Ao Departamento de Agroindústria, Alimentos e Nutrição da Escola Superior de Agricultura "Luiz de Queiroz" da Universidade de São Paulo, pela oportunidade concedida. 


\section{SUMÁRIO}

Página

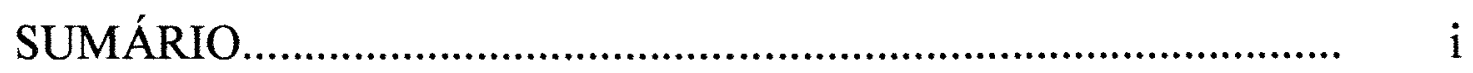

LISTA DE APÊNDICES........................................................ iv

LISTA DE FIGURAS................................................................. v

LISTA DE TABELAS............................................................. vii

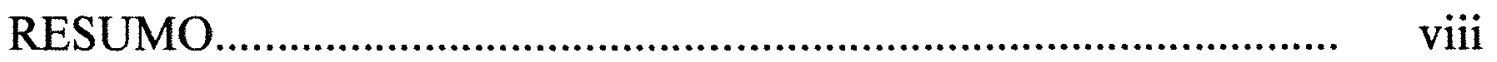

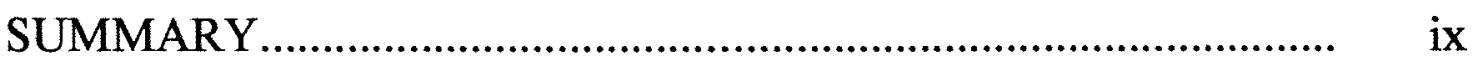

1. INTRODUÇÃO....................................................................

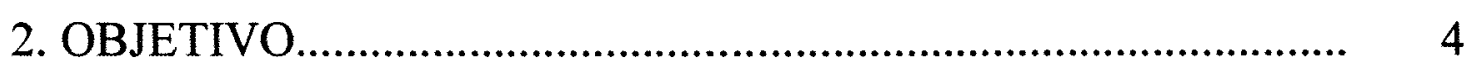

3. REVISÃO DE LITERATURA................................................ 5

3.1. Generalidades.................................................................. 5

3.2. Composição da aguardente e suas relações com o processo e a qualidade........................................................................... 8

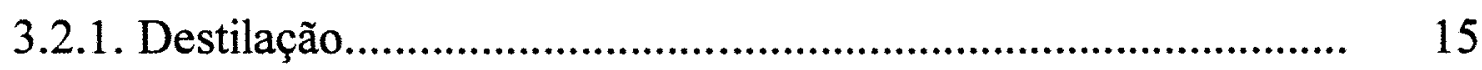

3.2.2. Envelhecimento.................................................................. 18

4. MATERIAIS E MÉTODOS................................................... 20

4.1. Matéria-prima.......................................................................... 21

4.2. Condução da destilação.............................................................. 21

4.2.1. Processo convencional............................................................... 21

4.2.2. Processo da dupla destilação..................................................... 22 
4.2.2.1. Obtenção do flegma........................................................ 22

4.2.2.2. Obtenção do destilado final.............................................. 23

4.3. Padronização dos destilados................................................... 24

4.4. Análises físico-químicas................................................... 25

4.4.1.Densidade...................................................................... 25

4.4.2. Acidez volátil................................................................. 26

4.4.3. Acidez fixa.................................................................... 26

4.4.4. Furfural............................................................................ 26

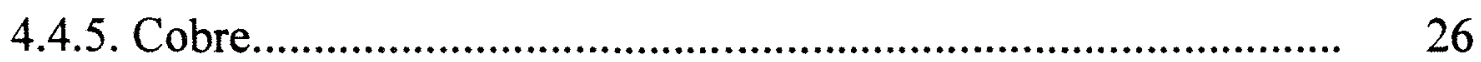

4.4.6. Análise cromatográfica................................................... 26

4.5. Análise sensorial............................................................... 27

4.5.1. Teste triangular de diferença............................................... 27

4.5.2. Teste pareado de preferência............................................. 28

4.6. Análise estatística.............................................................. 28

5. RESULTADOS E DISCUSSÃO ............................................. 29

5.1. Análises de vinho.............................................................. 29

5.2. Análise da condução da destilação......................................... 30

5.2.1. Processo convencional....................................................... 30

5.2.2. Processo da dupla destilação............................................. 33

5.2.2.1. Obtenção do flegma......................................................... 33

5.2.2.2. Obtenção do destilado final............................................. 35

5.3. Análise comparativa entre as aguardentes............................. 38

5.3.1. Acidez total.................................................................... 39

5.3.2. Densidade e grau alcoólico............................................... 40

5.3.3. Furfural......................................................................... 41 
5.3.4. Cobre......................................................................... 42

5.3.5. Aldeídos............................................................................ 45

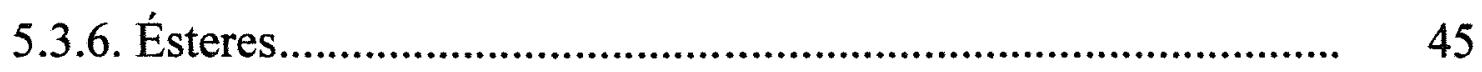

5.3.7. Álcoois superiores................................................................ 46

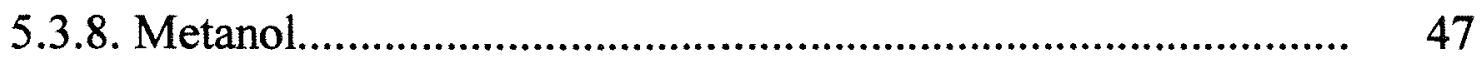

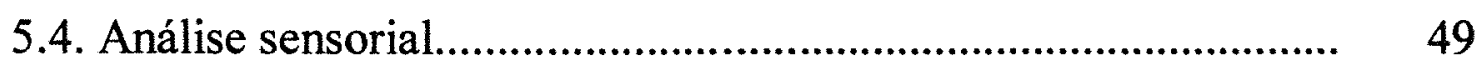

5.4.1. Teste triangular de preferência.................................................. 49

5.4.2. Teste pareado de preferência..................................................... 50

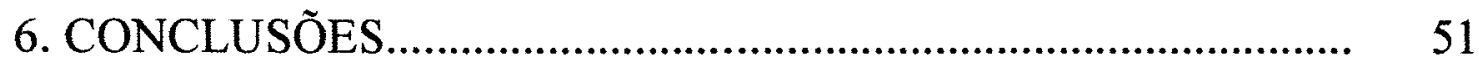

7. REFERÊNCIAS BIBLIOGRÁFICAS......................................... 52 


\section{Lista de Apêndices}

Página

Análise das aguardentes bidestiladas bloco a bloco...................... $\quad 60$

Análise das aguardentes monodestiladas bloco a bloco................ 61 


\section{LISTA DE FIGURAS}

Página

Figura 1. Quantidade de etanol nos vinhos e nos destilados Tratamento AM

Figura 2. Eficiência de destilação segundo o líquido gerador Tratamento AM

Figura 3. Quantidade de etanol nos vinhos e nos destilados Tratamento $\mathrm{AB}$.

Figura 4. Eficiência de destilação segundo o líquido gerador Tratamento $\mathrm{AB}$.

Figura 5. Teores alcoólicos dos flegmas e volumes de coração obtidos - Tratamento AB.

Figura 6. Volume de coração obtido em função do teor alcoólico do líquido gerador (flegma)

Figura 7 Acidez total das amostras. 
Figura 8 Densidade das amostras.............................................. 41

Figura 9. Teores alcoólicos das amostras..................................... 41

Figura 10. Cobre em função da acidez total - Tratamento AB........ 43

Figura 11. Cobre em função da acidez total - Tratamento 44 AM........

Figura 12. Teores de ésteres nas amostras................................. 46

Figura 13. Teores de álcoois superiores das amostras.................. 47

Figura 14. Teores de metanol nas amostras................................. 48 


\section{LISTA DE TABELAS}

Página

Tabela 1. Caracterização dos vinhos segundo o grau alcoólico....... 29

Tabela 2. Parâmetros de destilação do tratamento AM 30

Tabela 3. Parâmetros de destilação do tratamento AB 33

Tabela 4. Quantidades de produto e de etanol - Tratamento AB..... 35

Tabela 5. Análise físico-química entre os tratamentos................... 38

Tabela 6. Teste triangular de diferença entre os tratamentos...........

Tabela 7. Teste triangular de diferença entre as amostras do mesmo tratamento. 50

Tabela 8. Teste pareado de preferência. 


\title{
INFLUÊNCIA DA CONDUÇÃO DA DUPLA DESTILAÇÃo NAS CARACTERÍSTICAS FÍSICO-QUIMICAS E SENSORIAIS DA AGUARDENTE DE CANA
}

\author{
Autor: Leandro César Bizelli \\ Orientador: Fernando Valadares Novaes
}

\section{RESUMO}

Este Trabalho foi desenvolvido com o objetivo de avaliar a influência da condução da destilação sobre as características físico-químicas e sensoriais da aguardente de cana.

Duas técnicas de destilação em alambique simples foram confrontadas, a destilação convencional (Tratamento A.M.) e a dupla destilação (Tratamento A.B.).

Os resultados mostraram a influência positiva da dupla destilação sobre as características físico-químicas da aguardente, com redução nos teores de aldeídos, ésteres e principalmente cobre e acidez acética, dentre outros parâmetros tecnológicos analisados. 


\title{
DOUBLE DISTILLATION INFLUENCE ON PHYSIC- CHEMICAL AND SENSORIAL CHARACTERISTICS OF SUGAR CANE SPIRIT
}

\author{
Author: Leandro César Bizelli \\ Adviser: Fernando Valadares Novaes
}

\section{SUMMARY}

The aim of this work was to evaluate the distillation conduction on physic-chemical and sensorial characteristics of the sugar cane spirit.

Two distillation techniques, employing pot still, were compared: the conventional distillation and the double distillation.

The results showed positive influence of the double distillation on the physic-chemical spirit characteristics, leading to lower levels of aldehydes, esters, copper and total acidity, besides the others technological parameters studied. 


\section{INTRODUÇÃO}

A produção de aguardente de cana teve início nos primórdios de nossa colonização, logo que os canaviais foram plantados e os engenhos de açúcar passaram a moer cana.

A aguardente de cana, cachaça ou caninha, denominações oficiais, além de uma infinidade de outros nomes populares, é uma bebida tipicamente brasileira, assim como a vodca, o uísque, a tequila, e o conhaque, dentre muitas outras, fazem parte da história política, social, cultural e econômica de cada país de origem.

Compõe bebidas típicas, torna-se remédio através de infusões e macerações com ervas e raizes. Desde os tempos do Brasil Colônia tem participação importante em nossa economia, quer como fonte de renda para meeiros e arrendatários ou como moeda para contrabandistas que a trocavam por escravos na costa africana no denominado comércio triangular.

É produzida praticamente em todo território nacional, apresentando números contraditórios quanto ao volume de produção. Estimativas mais conservadoras apontam para 1,2 bilhão de litros anuais, ao passo que outras arriscam valor superior a 2,0 bilhões de litros. 
Movimenta um mercado que fatura aproximadamente US\$ 5 bilhões, dividido praticamente só por indústrias nacionais. É o destilado mais consumido no mundo, a segunda bebida alcóolica mais consumida no Brasil; estima-se um consumo per capita ao redor de 10 litros/ano, contra 48 litros/ano da cerveja com volume de 7,2 bilhões de litros/ano. Considerando-se que a graduação alcoólica da cerveja situa-se em torno de $10 \%$ dos teores encontrados na aguardente de cana comercial, observa-se que o consumo de etanol via aguardente de cana é superior ao da cerveja.

Apesar do grande volume produzido e comercializado, a qualidade de grande parte das aguardentes deixa muito a desejar, devido ao fato de muitos leigos ou mesmo curiosos estarem à frente das unidades produtoras, executando o processo de maneira empírica e rudimentar, baseados no senso comum e informações errôneas que muitas vezes passam de pai para filho.

A busca de qualidade é o objetivo principal de qualquer indústria que procura ampliar seu mercado e conquistar novos consumidores e, na produção de aguardente não poderia ser diferente.

Para se ter qualidade é necessário, antes de tudo, elaborar o produto, porém qualidade só será alcançada e controlada se a indústria conhecer cientificamente, o processo e o produto. Qualidade se consegue com tecnologia; assim, urge a necessidade de pesquisas e publicações que possam responder às necessidades do setor. 
Porém, fica dificil falar-se em qualidade, na acepção exata da palavra, conhecendo-se as condições operacionais de produção da aguardente de cana, onde se observam falhas na colheita e preparo da matéria-prima, no processo de fermentação e destilação, e até mesmo no armazenamento do produto final.

Ao contrário de outros povos que desenvolveram, aprimoraram e divulgaram seus destilados, aqui a aguardente é considerada bebida de segunda categoria, porém, a adequação e inovação dos processos, aos poucos têm rendido bons frutos no que se refere à qualidade. Conseqüentemente, surgem novos mercados e novos consumidores. Assim é que o processo de dupla destilação, usual na grande maioria dos outros destilados, vem de encontro com a busca da tão almejada qualidade, mostrando-se como uma alternativa para a melhoria da qualidade da aguardente de cana. 


\section{OBJETIVOS.}

O trabalho teve como objetivo a avaliação da aguardente de cana produzida pelo processo dupla destilação, através de um ensaio comparativo com a aguardente obtida pelo processo convencional de destilação. 


\section{REVISÃO DE LITERATURA.}

\subsection{Generalidades.}

A produção de aguardente de cana teve início nas primeiras décadas após o descobrimento do Brasil, logo após a introdução da cultura da cana-de-açúcar em terras brasileiras, ocasião em que os engenhos de açúcar passaram a moer cana ( Lima, 1999).

A aguardente de cana é definida pela Legislação como bebida alcoólica obtida a partir da destilação do caldo de cana fermentado. Deve apresentar teor alcoólico entre 38 e $54 \%$ em volume a $20{ }^{\circ} \mathrm{C}$ e poderá ser denominada envelhecida se contiver um mínimo de $50 \%$ de destilado alcoólico simples envelhecido, sendo permitida a adição de caramelo para correção da cor. Pode também conter até $6 \mathrm{~g}$ de açúcar por litro para correção do sabor, porém, se contiver mais de $6 \mathrm{~g}$ e menos de $30 \mathrm{~g}$ por litro, o produto deverá ter sua denominação acrescida da expressão "adoçada" (Brasil, 1997).

No Brasil, consomem-se 30.000 doses por minuto, 500 doses por segundo, sendo que $75 \%$ do total produzido são originários das destilarias de médio e grande portes, nas quais se destaca o processo de destilação contínua, através das denominadas colunas de destilação. 
Algumas dessas unidades industriais superam a marca de 300.000 litros diários e, assim, chegam a produzir quantias superiores a 50 milhões de litros, em um período de 150 a 180 dias de safra.

Quanto aos 25\% restantes, são originados dos chamados engenhos ou alambiques que, embora com produções individuais pequenas (100 a 1000 litros/dia), encontram-se espalhados em todos os Estados brasileiros, com maior concentração em Minas Gerais. A principal característica dessas pequenas unidades é a de apresentarem, em sua maioria, uma produção marginal, sem registro legal, cujo produto final é mais comercializado local ou regionalmente.

O que sempre se soube a respeito da aguardente, é que se trata de uma bebida barata, consumida basicamente nos "pontos de dose", bares e restaurantes, responsáveis por $92 \%$ das vendas.

Após a fermentação, o mosto de cana passa a ser chamado vinho. Compõe-se de água e álcool etílico em maiores proporções, e muitos outros compostos que constituem a chamada "fração não álcool", também denominada "componentes secundários" ou simplismente "congêneres", substâncias essas responsáveis pelo sabor e aroma da bebida. Quantitativamente os principais componentes da fração não álcool são: aldeído acético, ácido succínico, ácido acético e ésteres desses ácidos, glicerina, furfural e álcoois superiores como o amílico, isoamílico, butílico, isobutílico, propílico, e isopropílico (Lima, 1983).

A qualidade das aguardentes não está sujeita somente à sua composição qualitativa em ésteres, ácidos, álcoois e aldeídos, mas principalmente pela participação quantitativa destes elementos que condicionam o aroma e o sabor típico das aguardentes. A qualidade 
depende, entre outras variáveis, da natureza e composição dos vinhos, do tipo de aparelho de destilação e da sua condução operacional. Estes fatores controlam e determinam o buquê das aguardentes, que é resultante da combinação de aromas dos não-álcoois presentes ( Stupiello, 1992).

De acordo ainda com este autor, a prática da destilação para a obtenção da aguardente normalmente é realizada em aparelhos descontínuos (destilação simples) ou em aparelhos contínuos (destilação sistemática). Dentre os primeiros, os mais empregados são os alambiques simples e o de três corpos; dentre os últimos, as torres ou colunas de destilação. Os alambiques, apesar dos limitados recursos, podem fornecer aguardente de boa qualidade dependendo das condições operacionais.

De acordo com Decreto Federal ( Brasil, 1974), a aguardente de cana deve se enquadrar nos Padrões de Identidade e Qualidade assim definidos:

Acidez volátil expressa em mg de ácido acético $\times 100 \mathrm{~mL}^{-1}$ de álcool anidro: máximo de 150;

Ésteres, expressos em $\mathrm{mg}$ de acetato de etila $\times 100 \mathrm{~mL}^{-1}$ de álcool anidro: máximo de 200;

Aldeídos, expressos em $\mathrm{mg}$ de aldeído acético $\mathrm{x} 100 \mathrm{~mL}^{-1}$ de álcool anidro: máximo de 30;

Álcool superior, expressos em $\mathrm{mg} \times 100 \mathrm{~mL}^{-1}$ de álcool anidro máximo: 300;

Álcool metílico em mg x $100 \mathrm{~mL}^{-1}$ de álcool anidro: máximo de 200;

Congêneres, em mg x $100 \mathrm{~mL}^{-1}$ de álcool anidro: mínimo de 200; 
Cobre: máximo de $5 \mathrm{mg} \times \mathrm{L}^{-1}$.

\subsection{Composição da aguardente e suas relações com o processo e a qualidade.}

Análises efetuadas por cromatografia gasosa têm demonstrado que, além da água e do álcool etílico, um destilado bruto apresenta cerca de duas centenas de outros componentes voláteis, dos quais a quase totalidade tem natureza líquida. Considerando individualmente aquelas substâncias, verifica-se que seus pontos de ebulição variam desde $19^{\circ} \mathrm{C}$ até $268^{\circ} \mathrm{C}$, sendo muito próximos uns dos outros e, algumas vezes, praticamente coincidentes. Tal fato, por si só já demonstra a dificuldade em separá-los do álcool etílico, aliado ainda à miscibilidade que ocorre entre algumas das substâncias e em relação ao próprio álcool (Novaes, 1994).

Segundo Ernesto Sorel, citado por Novaes (1994) as impurezas são geralmente muito solúveis no álcool etílico e pouco ou insolúveis na água, e quando esta constitui a parte dominante do líquido em destilação (líquido gerador a baixo grau) a impureza considerada se comporta como um líquido não miscível e portanto, a sua tensão de vapor é pouco influencia na separação, consequentemente as impurezas são facilmente arrastadas pelos vapores alcoólicos.

Segundo Barbet, citado por Novaes (1994), no que diz respeito à volatilidade, são denominados de produtos de "cabeça" aqueles que apresentam ponto de ebulição inferior ao do álcool etílico e produtos de "cauda os que possuem ponto de ebulição superior a ele. Contudo, 
determinados compostos se comportam ora como produtos de "cabeça", ora como produtos de "cauda", segundo a concentração alcoólica do líquido submetido à destilação.

Durante a destilação, a parcela inicial dos vapores que sai do aparelho é rica em substâncias mais voláteis, embora encerre também teor significativo de álcool etílico, vindo a constituir os produtos de cabeça. Prosseguindo a operação, tais substâncias diminuem e se originam vapores alcoólicos mais puros, constituindo o produto de coração. No final, destilam em grande quantidade as substâncias menos voláteis compondo os produtos de cauda. Não se deve supor, entretanto, que na primeira etapa passem somente e todas as impurezas mais voláteis, nem que na última etapa passem somente e todas as substâncias menos voláteis. Das primeiras existem traços no produto fino ( ${ }^{\infty}$ coração"), assim como traços dos menos voláteis também são arrastados pelas porções iniciais (Novaes, 1994).

Os componentes voláteis do vinho possuem diferentes graus de volatilidade, sendo possível a separação por processo de destilação. Assim, os componentes mais voláteis são recolhidos na primeira fração do destilado denominado de "cabeça", e os menos voláteis nas frações finais, "cauda". A porção intermediária é conhecida como "coração" e é constituída principalmente de frações medianamente voláteis (Yokoya, 1995).

Yokoya (1995) acrescenta ainda que o comportamento dos compostos secundários na destilação depende das suas propriedades termodinâmicas. Os diversos compostos secundários no vinho podem ser agrupados em três categorias: 
(1) Compostos mais voláteis que o álcool, representados por ésteres e muitos aldeídos, são mais freqüentes na fração "cabeça".

(2) Compostos menos voláteis que o álcool, representados por compostos fenólicos e muitos ácidos orgânicos, são mais abundantes na fração "cauda".

(3) Compostos que são mais voláteis que o álcool nas soluções alcoólicas de baixa concentração e menos voláteis nas soluções alcoólicas concentradas.

Segundo Gutierrez (1989), poucos trabalhos desenvolvidos deram ênfase à formação de compostos secundários da fermentação alcóolica do caldo de cana, principalmente os álcoois superiores, que são componentes importantes para formação do aroma e palatabilidade de bebidas alcoólicas.

Dentre as principais causas que conduzem a variações na composição e qualidade das aguardentes de cana destaca-se a destilação, com ou sem fracionamento dos produtos de "cabeça" "coração e e cauda" ( Lima, 1964).

O desenho, a montagem e a construção do aparelho destilatório, bem como a maneira de conduzir o processo de destilação ocupam lugar de importância como fatores que interferem na qualidade da aguardente de cana (Almeida, 1940).

A condução da destilação é fundamental na obtenção de bebida de qualidade, pois promove uma mudança na proporção dos componentes não álcoois, que formaram o "bouquet"característico da bebida (Souza \& Llistó,1978). 
Quanto à origem metabólica das substâncias aromáticas presentes nas bebidas alcoólicas, pode-se dizer que algumas delas estão presentes na matéria- prima usada na manufatura da bebida. Podem permanecer inalteradas durante a fermentação, podem ser quimicamente modificadas pelas leveduras ou durante a destilação, originando compostos que influenciam no flavor do produto (Boza, 1996).

De acordo com Ribeiro e Horii (1998), parâmetros de qualidade são escassos uma vez que a legislação em vigor pouco rege sobre este atributo, impondo limites para garantia da saúde publica, e que pouco ou nada se refere à qualidade global do produto.

Dentre estes parâmetros, de especial interesse é o teor de cobre, o qual em muito tem limitado as exportações de aguardente pelas imposições legais dos potenciais países importadores (Oliveira, 1970; Faria \& Campos, 1989 )

Este metal é dissolvido na parte descendente do aparelho de destilação ( Faria, 1989 ) pela dissolução do carbonato básico de cobre (azinhavre) que se forma em seu interior (Lucena, 1957).

Vários autores atribuem o arraste de cobre pela fração "cabeça", devido a esta possuir a totalidade do ácido acético do vinho ( Chaminade, 1930 ) e pela fração correspondente à "cauda", devido a sua temperatura elevada que favorece a dissolução do azinhavre na sua passagem pelo condensador ( Lima, 1964) e também pelo aumento da acidez por ácidos graxos menos voláteis ( Pacottet, 1922); (Ribeiro \& Horii,1998.)

Ribeiro (1997) mostra que durante o decorrer da destilação as primeiras porções do destilado possuem acidez elevada, diminuindo na 
parte intermediária, voltando a se elevar na parte final, dados anteriormente relatados por Lafon (1964) e Boza (1996).

Segundo Ribeiro \& Prado Filho (1997) o cobre é elemento essencial para todos os vertebrados, moluscos e crustáceos; quando ingerido em excesso causa sérias anomalias ao organismo humano, sendo que sua falta também é prejudicial.

As anomalias devidas à deficiência de cobre são;

- anemia em função da diminuição da formação de hemoglobina;

- defeitos esqueléticos;

- redução na formação de elastina;

- teratogênese;

- atividade anormal da amino-oxidase, afetando o metabolismo dos carboidratos e a biossíntese de catecolamina;

- defeitos em pigmentação e estrutura capilar; lesões cardiovasculares.

Por outro lado, os sintomas de intoxicação resumem-se em:

- intoxicação aguda: caracterizada por sintomatologia que se estende desde disturbios gastroentestinais, dores de cabeça, sabor metálico na boca, anemia hemolítica, falhas renais e hepáticas, até a morte; - intoxicação crônica: trata-se da Doença de Wilson, descrita inicialmente por Kinner Wilson em 1912 que a caracterizou como disturbio nervoso associado à cirrose hepática em função do acúmulo de cobre no figado, cérebro e rins; recentemente novos estudos sugerem que a doença se deve a um problema genético que se expressa por um defeito no sistema de excreção de cobre, dado pela ensima ATPase. 
Um comitê especial da Food and Agriculture Organization / World Health Organization ( FAO / WHO ) recomenda uma ingestão total de cobre por adultos durante um longo período de tempo esteja na média de 2 a $3 \mathrm{mg} / \mathrm{dia}$, e ainda determinou que efeitos não deletérios em homens poderiam ser esperados para uma administração de cobre de $0,5 \mathrm{mg} / \mathrm{Kg}$ de peso vivo por dia.

Os álcoois superiores conferem corpo à bebida, além de alguns esterificarem durante $\mathrm{o}$ envelhecimento $\mathrm{e}$ seus ésteres são aromaticamente mais agradáveis (Guymon, 1972).

Os álcoois superiores não são importantes apenas pelo seu odor característico, mas também devido à sua ação solvente sobre outras substâncias aromáticas, interferindo no seu grau de volatilidade (Amerine et al. 1972).

Os ésteres são, numericamente, o maior grupo de componentes do aroma das bebidas destiladas, seu limiar sensorial é muito baixo e confere "flavours" característicos, até mesmo quando presentes em baixa concentração, porém, a composição qualitativa dos ésteres é altamente similar em todas as bebidas alcoólicas (Suomalainen, 1981).

Qualitativamente, os componentes do aroma da aguardente são os mesmos encontrados nas demais bebidas alcoólicas fermentadas e destiladas ( Maia, 1994).

Os ésteres, de modo geral são desejáveis, pois favorecem o aroma da aguardente, sendo oriundos da fermentação, da destilação e do processo de envelhecimento (Simpson, 1971). 
$\mathrm{O}$ acetato de etila, que corresponde a cerca de $80 \%$ do conteúdo total de ésteres da aguardente, é formado durante a fermentação e na destilação, como produto de reação de esterificação entre álcool etílico e ácido acético; confere odor $\mathrm{e}$ gosto desagradaveis à aguardente (Hashizume, 1976).

Os ácidos orgânicos voláteis são os mais comuns em bebidas destiladas, sendo o ácido acético o mais abundante ( Rose, 1977).

A maioria dos aldeídos em bebidas alcoólicas, é formada durante a fermentação, sendo produtos intermediários da rota biosintética dos álcoois superiores (Suomalainiem \& Lehtonen, 1979).

Os principais aldeídos encontrados em aguardentes são: acético, fórmico, butírico, isobutírico, valérico, e capróico, entre outros. Grande parte da fração aldeídica presente no vinho é separada durante a destilação como produtos de "cabeça", as aguardentes ricas em aldeídos são provenientes de alambiques que não separam os produtos de cabeça durante a destilação ( Póvoa \& Chaves, 1992 ).

O furfural é um aldeído comum em produtos provenientes de vinhos de cereais sacarificados por processo ácido ou mostos ricos em carboidratos ou muito turvos, seu aparecimento é promovido por superaquecimento na destilação que promove a pirogenação da matéria orgânica. Para evitar o aumento de furfural na aguardente deve-se destilar o vinho o mais limpo possivel, livre de substâncias orgânicas em suspensão( Póvoa \& Chaves, 1992 ). 


\subsubsection{Destilação.}

Os vinhos contêm um grande número de compostos voláteis que destilam segundo três critérios: ponto de ebulição, afinidade com o álcool ou água e teor alcoólico no vapor durante a destilação (Léauté, 1990), sendo que em função do grau de volatilidade, o destilado é dividido em três frações: cabeça, coração e cauda (Suomalainen \& Nykanen, 1966).

O comportamento das diferentes impurezas (compostos secundários) em relação ao álcool etílico no decorrer de qualquer operação de destilação está relacionada às suas diferentes solubilidades no etanol, segundo Ernesto Sorel citado por Novaes (1994).

Segundo Williams \& Strauss (1976), na manufatura de bebidas alcoólicas a partir da destilação de vinhos, as impurezas de baixo ponto de ebulição são coletadas na fração denominada "cabeça", essa fração tem um volume de 5 a $15 \%$ do produto, dependendo do tipo e condição da destilação, e possui um teor alcoólico mínimo de $80 \%$, além de compostos altamente indesejáveis como acetato de etila, acetaldeído, entre outros.

Durante a destilação do vinho para obtenção do conhaque, ou aguardente de uva, procedem-se duas destilações; a primeira destilação do vinho é levada a efeito até que o alcoômetro marque zero. Este primeiro destilado é, a seguir, fracionado numa segunda destilação em três porções:

A primeira fração, denominada "cabeça", é representada pela porção inicial do destilado com teor alcóolico de 78 a $88^{\circ} \mathrm{GL}$, até atingir 70 a $76,5^{\circ} \mathrm{GL}$ no conjunto(teor médio). 
Segundo alguns autores, seu volume é variável: 0,625 a $1,250 \%$ do volume do vinho (Baudoin, 1905), 1\% da capacidade da caldeira (Pacottet, 1922).

As primeiras porções apresentam cheiro desagrádavel, cơm elevado teor alcoólico, água, éter etil acético, pequena porção de éter propiônico, a totalidade do ácido acético, e ainda certa porção de álcoois superiores, de furfural e acetona (Chaminade, 1930).

A segunda fração é constituída pelos produtos do "coração" e compreendem as porções que destilam de 70 a $76,5{ }^{\circ} \mathrm{GL}$ até $50{ }^{\circ} \mathrm{GL}$, ficando o conjunto com 67,8 a $70,3^{\circ} \mathrm{GL}$ (Baudoin, 1905).

Os produtos do "coração constituem a aguardente mais fina. São produtos odorantes úteis, que contribuem para qualidade do produto, tais como ácidos graxos, ésteres, aldeídos, furfural e álcoois superiores.

A última fração forma os produtos da cauda, reunindo todos os produtos que destilam de 50 a $0^{\circ} \mathrm{GL}$, acusando o conjunto $22{ }^{\circ} \mathrm{GL}$ (Pacottet, 1922).

São produtos de cauda o álcool, água, álcoois superiores, ácidos graxos menos voláteis, furfural e ésteres.

O método tradicional de fabricação de conhaque é feito em dupla destilação; na primeira destilação obtem-se um destilado cuja graduação alcóolica é de 25 a $30^{\circ} \mathrm{GL}$; na segunda, a graduação alcoólica sobe para cerca de $70^{\circ} \mathrm{GL}$. Tanto o início da produção, a chamada "cabeça", como o final, a "cauda", são eliminados; apenas o corpo ou "coração" é usado para elaboração do conhaque.

Essa técnica com dupla destilação faz com que a bebida fique com menos impurezas, tornando-se um destilado bem delicado. É 
feito então o corte, mistura do conhaque com água destilada e desmineralizada, para chegar aos 40 ou $42{ }^{\circ} \mathrm{GL}$.

$\mathrm{Na}$ fabricação de conhaque se procedem duas destilações em método aperfeiçoado utilizando-se dois corpos de alambique; o primeiro denominado "wash still ${ }^{\circ}$ ou caldeira de esgotamento e o segundo "low wine still $^{\circ}$ ou caldeira de destilação. A primeira destilação, do vinho, procede até o destilado conter um teor alcoólico de $20 \%$; esse é redestilado no "low wine still ${ }^{\infty}$ até resultar num destilado cujo teor alcoólico varia de 35 a $60 \%$ (Hirsch, 1937).

$\mathrm{Na}$ fabricação de uísque, a primeira destilação levará à obtenção do "low wine", uma bebida ainda de pouca graduação alcoólica que, numa segunda destilação, resultará no uísque, com cerca de $58^{\circ} \mathrm{GL}$, que é corrigido com água e levado a envelhecer em barris de carvalho(Os Segredos..., 1991).

De acordo com Almeida (1952), para produzir aguardente de cana recomenda-se separar $10 \%$ dos produtos de cabeça, $80 \%$ dos produtos de coração e $10 \%$ dos produtos de cauda. Os produtos cabeça e cauda são misturados e incorporados a outro vinho para nova destilação.

Lucena (1957) recomenda para se obter aguardente de boa qualidade a adoção da seguinte prática: a fração cabeça é separada quando o alcoômetro marcar 80 a $85^{\circ} \mathrm{GL}$; em seguida destila o coração de 80 a 85 ${ }^{\circ} \mathrm{GL}$ à $45^{\circ} \mathrm{GL}$, originando um produto com uma riqueza alcoólica média de 55 a $65^{\circ} \mathrm{GL}$, e finalmente a cauda, sendo que os produtos extremos são adicionados na destilação posterior.

Durante a destilação, a maior parte do metanol e dos aldeídos voláteis deve permanecer no destilado de cabeça. Através do 
controle da destilação, os álcoois superiores, os ésteres e os ácidos podem ser direcionados para o destilado de cauda, restringindo-se a fração remanescente na aguardente apenas os valores correspondentes à faixa permitida por lei e, dentro desta, aos níveis mais adequados para a qualidade sensorial da bebida (Maia, 1994).

\subsubsection{Envelhecimento.}

O envelhecimento sistemático da aguardente de cana não é uma prática normal no Brasil, mas tem-se observado melhora sensível no aroma e sabor com armazenamento prolongado do produto definido como "redondo","liso"e "suave" (Yokoya, 1995).

O conhaque quando jovem é agressivo, forte e incompleto. Portanto, envelhecer em barris de carvalho é uma etapa tão importante quanto os cuidados com a destilação (Castilho, 1991).

No decorrer do envelhecimento ocorre redução dos ácidos e aldeídos, assim como aumento dos ésteres. Além disso vários compostos fenólicos, provenientes da madeira, deverão incorporar-se progressivamente à bebida (Maia, 1994).

O desenvolvimento do aroma e sabor durante o envelhecimento é resultante de uma série de transformações lentas e relativamente independentes que, somadas, dão origem às propriedades características de cada bebida após alguns anos de envelhecimento (Yokoya, 1995).

No envelhecimento, o recipiente $e$ as condições de armazenagem são responsáveis pelas alterações das características 
sensoriais do destilado. O recipiente afeta essas características de forma subtrativa, removendo algumas substâncias por meio de evaporação, adsorção ou interação com o material usado no recipiente; de forma aditiva, incorporando algumas substâncias constituintes do recipiente no produto e, de forma indireta (interativa), onde o produto liberado do recipiente reage oxidativamente com o destilado para dar o sabor agradável ao produto (Wildenradt \& Singleton, 1984).

Como pode ser observado, os princípios tecnológicos são de natureza complexa, mas os requisitos básicos para produção de aguardente de qualidade são acessíveis a todos os produtores, independente da escala de produção (Maia, 1994 ).

Segundo dados do Instituto VINEXPO, o consumo de destilados cresce significativamente. A preferência se concentra nos destilados de média e alta qualidade bem como para as grandes marcas (Mercado Mercantil, 1995).

Pesquisas a nível nacional apontam que alterações na qualidade da aguardente resultariam em uma melhor acolhida do produto não só pelos consumidores, como também por parte dos atuais não consumidores (Lima Neto \& Franco, 1994). 


\section{MATERIAIS E MÉTODOS.}

Os ensaios foram realizados na planta piloto da destilaria “ Professor Juvenal Mendes de Godoy" e junto aos laboratórios do Departamento de Agroindústria, Alimentos e Nutrição da Escola Superior de Agricultura "Luiz de Queiroz"/ Universidade de São Paulo.

O trabalho constituiu na comparação entre aguardentes produzidas por dois métodos distintos de condução de destilação: destilação convencional e dupla destilação, sendo desenvolvido sob condições operacionais práticas, ou seja, vinho sem padronização, sem controle na pressão de vapor e consequentemente sem controle na velocidade de destilação, assim como conduzido na maioria das unidades produtoras.

Desta forma, visando o estudo do efeito da condução da destilação sobre a qualidade físico-química e sensorial da aguardente de cana, foram realizados ensaios comparativos entre duas técnicas diferenciadas de condução da destilação. 


\subsection{Matéria-prima.}

Para a produção dos destilados, foram utilizados vinhos centrifugados oriundos da fermentação alcoólica do mosto de cana-deaçúcar. O teor alcoólico desses vinhos situou-se no intervalo de 6,5 a $8,35 \%$ em volume, a $20{ }^{\circ} \mathrm{C}$.

\subsection{Condução da destilação.}

Duas diferentes técnicas de condução de destilação constituíram os tratamentos destes ensaios, onde a destilação pelo processo convencional ( tratamento A.M. ) deu origem à aguardente monodestilada, e a técnica da dupla destilação ( tratamento A.B. ) deu origem à aguardente bidestilada, conforme descrito adiante.

\subsubsection{Processo convencional.}

A destilação do vinho foi conduzida em dois alambiques de cobre "tipo cebola", volumes úteis de 106 litros, constituídos de caldeira de destilação assentada sobre base de alvenaria; capelo, seguido de uma alonga que termina em serpentina submersa em tanque com água corrente ( condensador/resfriadeira ). O sistema de aquecimento era indireto, através de vapor de água circulando no interior de serpentina submersa na carga de vinho ou seja, sem borbotagem de vapor no líquido gerador. $\mathrm{O}$ abastecimento dos alambiques era feito através de canalização própria que 
transportava o vinho da dorna volante para caixa de recalque, e desta para os alambiques, sob adequada assepsia das tubulações e dos equipamentos.

Após aquecimento, iniciada a corrida do destilado, o mesmo era recebido em recipiente à saída do registro, até que o seu teor alcoólico médio no interior deste recipiente coletor acusasse $45 \pm 1 \%$ em volume a $20^{\circ} \mathrm{C}$, quando então era considerada encerrada a operação. Este produto obtido por destilação simples foi posteriormente padronizado, originando a “aguardente monodestilada" ( Tratamento A.M. )

\subsubsection{Processo da dupla destilação.}

No processo da dupla-destilação ( Tratamento A.B. ), o vinho era destilado em uma primeira etapa dando origem ao "flegma"; este, por sua vez, sofria uma nova destilação dando origem à "aguardente bidestilada", seguindo metodologia descrita a seguir.

\subsubsection{Obtenção do flegma.}

A destilação do vinho para obtenção do flegma também foi conduzida nos alambiques descritos anteriormente.

Após aquecimento, iniciada a corrida do destilado, este era coletado em recipiente adequado, até que o seu teor alcoólico à saída do registro do condensador acusasse cerca de $5 \%$ de álcool em volume. Este processo de obtenção do flegma era realizado por três vezes, para se obter volume suficiente para preencher a carga útil do aparelho de destilação. 
Deste modo, ao final destas três destilações, os destilados obtidos com teor alcoólico médio de $21,4 \%$ em volume, a $20{ }^{\circ} \mathrm{C}$ eram misturados entre si, conseguindo-se então o volume necessário à redestilação.

\subsubsection{Obtenção do destilado final.}

O destilado final referente ao Tratamento A.B. foi obtido pela redestilação do flegma.

Para obtenção da "aguardente bidestilada", a mistura dos "flegmas" passou por uma segunda destilação, na qual houve fracionamento no recolhimento deste segundo destilado em frações denominadas "cabeças", "coração" e "cauda", com as seguintes características:

A fração "cabeças" correspondeu à parte inicial da corrida, cujo teor alcoólico médio esteve em torno de $70 \%$ em volume a $20{ }^{\circ} \mathrm{C}$, semelhante a técnica de Léauté (1990).

Da mesma forma a fração "coração", principal objetivo dessa segunda destilação, e que posteriormente seria utilizada na elaboração da aguardente bidestilada, correspondeu à parte intermediária da corrida, cujo teor alcoólico em volume esteve em torno de $65 \pm 1 \%$ a $20^{\circ} \mathrm{C}$.

A fração "cauda" correspondeu à parte final da corrida, isto é, do final da fração "coração" até que o teor alcoólico na corrida acusasse cerca de $5 \%$ em volume a $20^{\circ} \mathrm{C}$, pois com esta concentração de álcool na corrida, o teor alcoólico do flegma contido na caldeira já estaria praticamente esgotado, como recomendado por Valsechi (1970). 
As frações "cabeça" e "cauda" eram misturadas, constituindo-se em um líquido com teor alcoólico que variou de 20 a 30\% em volume a $20^{\circ} \mathrm{C}$. Cada terça parte desta mistura era adicionada a uma nova carga de vinho que, após destilação, originava o flegma. Assim, todo o volume da referida mistura era reciclado no processo, enriquecendo em álcool o vinho, permitindo, deste modo, recuperar boa parte do álcool ali contido.

\subsection{Padronização dos destilados.}

Estabeleceu-se que os produtos finais obtidos em ambos os processos deveriam apresentar um teor alcoólico da ordem de $40 \pm 1 \%$ em volume, a $20^{\circ} \mathrm{C}$.

Desse modo, através de Balanço de Massas, procedeu-se àquele ajuste, adicionando-se aos destilados água destilada para padronização de seus teores alcoólicos.

Após padronização, as amostras finais eram novamente acondicionadas em recipientes de vidro, tipo garrafão ( 4,6 litros ) e fechados com rolhas plásticas e armazenados à temperatura ambiente, assim permanecendo até o momento das análises a que seriam submetidas. 


\subsection{Análises fisico-químicas .}

As amostras foram coletadas diretamente de seus respectivos recipientes de armazenamento, sendo que referidas análises foram realizadas e submetidas às seguintes determinações analíticas:

\subsubsection{Densidade.}

A densidade serviu de medida indireta para a determinação do teor alcoólico, utilizando densímetro digital Anton-PAAR modelo DmA45, segundo Amorim et al ( 1982) e através de tabela de correspondência entre densidade e porcentagem de álcool em volume, a $20{ }^{\circ} \mathrm{C}$, foram obtidos os teores alcoólicos das frações destiladas ("flegma", "cabeças", "coração" e "cauda"), e também para a padronização das aguardentes.

No caso do vinho, foi ele previamente destilado em micro destilador Tecnal, sendo posteriormente, submetido ao mesmo sistema empregado para os destilados.

Determinações de teor alcoólico efetuadas no controle dos processos de destilação foram efetuadas por alcoômetros tipo Gay-Lussac, que apresentavam individualmente escalas alcoométricas volumétricas de 0 a 30,30 a 60 e 60 a $90 \%$, aferidos a $20^{\circ} \mathrm{C}$. 


\subsubsection{Acidez volátil.}

De acordo com as normas do Ministério da Agricultura, (1986).

4.4.3. Acidez fixa.

De acordo com as normas do Ministério da Agricultura, (1986).

\subsubsection{Furfural.}

De acordo com as normas do Ministério da Agricultura, (1986).

\subsubsection{Cobre.}

Determinado pelo método químico colorimétrico, descrito por Jacinto (1967).

\subsubsection{Análise cromatográfica.}

Os compostos voláteis ( aldeído acético, acetona, acetato de etila, metanol, N-propanol, I-butanol, I-amílico e N-amílico ) foram determinados 
por cromatografia em fase gasosa em cromatógrafo CG-37, com ionização de chama.

\subsection{Análise sensorial.}

Com o intuito de se verificar o efeito dos tratamentos sobre as características sensoriais dos destilados, as aguardentes obtidas foram submetidas ao Teste Triangular de Diferença e Teste Pareado de Preferência, ambos elaborados por equipe composta de 24 provadores previamente selecionados por meio de Teste Triangular (Mori, 1992 ).

Para se verificar a homogeneidade dos tratamentos, amostras de um mesmo tratamento foram também submetidas ao teste triangular de diferença.

As amostras submetidas ao teste sensorial foram compostas pela mistura de três outras amostras. Desta forma, tanto para o tratamento A.M. como para o tratamento A.B. utilizaram-se três amostras no teste sensorial.

\subsubsection{Teste triangular de diferença.}

O Teste Triangular de Diferença foi efetuado entre amostras do mesmo tratamento para se verificar se houve uniformidade nas condições de destilação, independente do tratamento a que foram submetidas, e também entre amostras de tratamentos diferentes para se verificar o efeito dos tratamentos sobre as características sensoriais dos destilados ( Mori, 1992 ). 


\subsubsection{Teste pareado de preferência.}

O Teste Pareado de Preferência foi efetuado entre amostras de tratamentos diferentes para verificar se os degustadores tinham preferência pelas aguardentes de um ou outro tratamento. As amostras foram servidas duas a duas, onde após aquele teste, o degustador manifestava sua preferência ( Mori, 1992 )

\subsection{Análise estatística.}

O ensaio foi conduzido sob o Delineamento de Blocos Casualizados, constituindo dois tratamentos ( destilação convencional e dupla destilação ) e nove blocos. Cada bloco compreendia os dois tratamentos de destilação de vinho oriundo da mesma batelada de fermentação, sistemática essa repetida no decorrer de todo processo de obtenção das amostras.

As médias obtidas dos tratamentos foram submetidas ao Teste $\mathrm{F}$ aplicado à Análise da Variância para se verificar se estas diferiam entre sí ao nível de $5 \%$ de probabilidade, segundo Pimentel Gomes ( 1990 ). 


\section{RESULTADOS E DISCUSSÃO.}

A seguir, são relatados os resultados das análises dos vinhos e dos destilados deles obtidos nos diferentes tratamentos.

\subsection{Análises de vinho.}

Os vinhos que serviram de matéria-prima para os diferentes tratamentos de destilação, ou seja, aguardente monodestilada e flegma para o tratamento de dupla-destilação, foram caracterizados segundo seus teores alcoólicos, conforme ilustrado pela tabela 1.

Tabela 1- Caracterização dos vinhos segundo o grau alcoólico.

\begin{tabular}{ccccccccccc}
\hline Bloco & 1 & 2 & 3 & 4 & 5 & 6 & 7 & 8 & 9 & Média \\
\hline$\%$ etanol $\left(\mathrm{v} . \mathrm{v}^{-1}\right)$ & 7,65 & 7,9 & 8,35 & 7,2 & 6,5 & 6,6 & 7,8 & 7,05 & 6,6 & 7,29 \\
\hline
\end{tabular}

Observou-se variação nos teores alcoólicos dos vinhos, com média de 7,29 $\pm 0,80 \%$ de etanol v/v, com nível de confiança de $95 \%$ e desvio padrão ( $\mathrm{s}$ ) de 0,66.

Esta variação no teor alcoólico dos vinhos é decorrente da variação no teor de sacarose do mosto que os originou, fato cuja ocorrência é comum nas unidades produtoras. 
5.2. Análise da condução da destilação.

\subsubsection{Processo convencional.}

A Tabela 2 mostra os dados obtidos para as amostras da aguardente monodestilada.

Tabela 2 - Parâmetros de destilação do Tratamento A.M.

\begin{tabular}{ccccccc}
\hline Bloco & $\begin{array}{c}\text { \% etanol } \\
\text { no vinho } \\
\left(\mathrm{v} . \mathrm{v}^{-1}\right)\end{array}$ & $\begin{array}{c}\text { Álcool do } \\
\text { vinho (L) }\end{array}$ & $\begin{array}{c}\text { Volume } \\
\text { de A.M. }\end{array}$ & $\begin{array}{c}\text { \% etanol A.M. } \\
\text { na }\end{array}$ & $\begin{array}{c}\text { na A.M. } \\
\text { n. }\end{array}$ & $\begin{array}{c}\text { Eficiência de } \\
\text { destilação }\end{array}$ \\
\hline 1 & 7,65 & 8,11 & 10,50 & 43,00 & 4,52 & 55,68 \\
2 & 7,90 & 8,37 & 12,00 & 45,20 & 5,42 & 64,77 \\
3 & 8,35 & 8,85 & 13,00 & 43,80 & 5,69 & 64,33 \\
4 & 7,20 & 7,63 & 9,50 & 45,00 & 4,28 & 56,01 \\
5 & 6,50 & 6,89 & 6,00 & 45,20 & 2,71 & 39,36 \\
6 & 6,60 & 7,00 & 5,50 & 44,20 & 2,43 & 34,75 \\
7 & 7,80 & 8,27 & 8,50 & 45,00 & 3,83 & 46,26 \\
8 & 7,05 & 7,47 & 9,00 & 45,10 & 4,06 & 54,32 \\
9 & 6,60 & 7,00 & 6,00 & 44,40 & 2,66 & 38,08 \\
\hline
\end{tabular}


Observaram-se variações tanto em volume quanto em grau alcoólico nas aguardentes monodestiladas produzidas. A média dos volumes e grau alcoólico foram $8,89 \pm 1,76$ litros e 44,54 $\pm 0,50 \%$ de etanol v/v, com desvios padrões de 2,69 e 0,76, respectivamente e nível de confiança de $95 \%$ para ambos os parâmetros. Tais variações podem ter sido decorrentes dos diferentes teores alcoólicos apresentados pelos respectivos vinhos.

Como pode ser observado através dos dados da tabela 2 , e das curvas das figuras 1 e 2 , o volume de álcool no destilado é diretamente proporcional ao volume de álcool no vinho; da mesma forma mostram que a eficiência de destilação varia de acordo com o teor alcoólico do vinho.

Nota-se que os melhores índices de eficiência de destilação aconteceram quando o teor alcoólico do vinho esteve acima de $7 \% \mathrm{v} / \mathrm{v}$, mostrando a conveniência em se destilar vinhos cujos teores alcoólico sejam maiores ou iguais a este valor. 


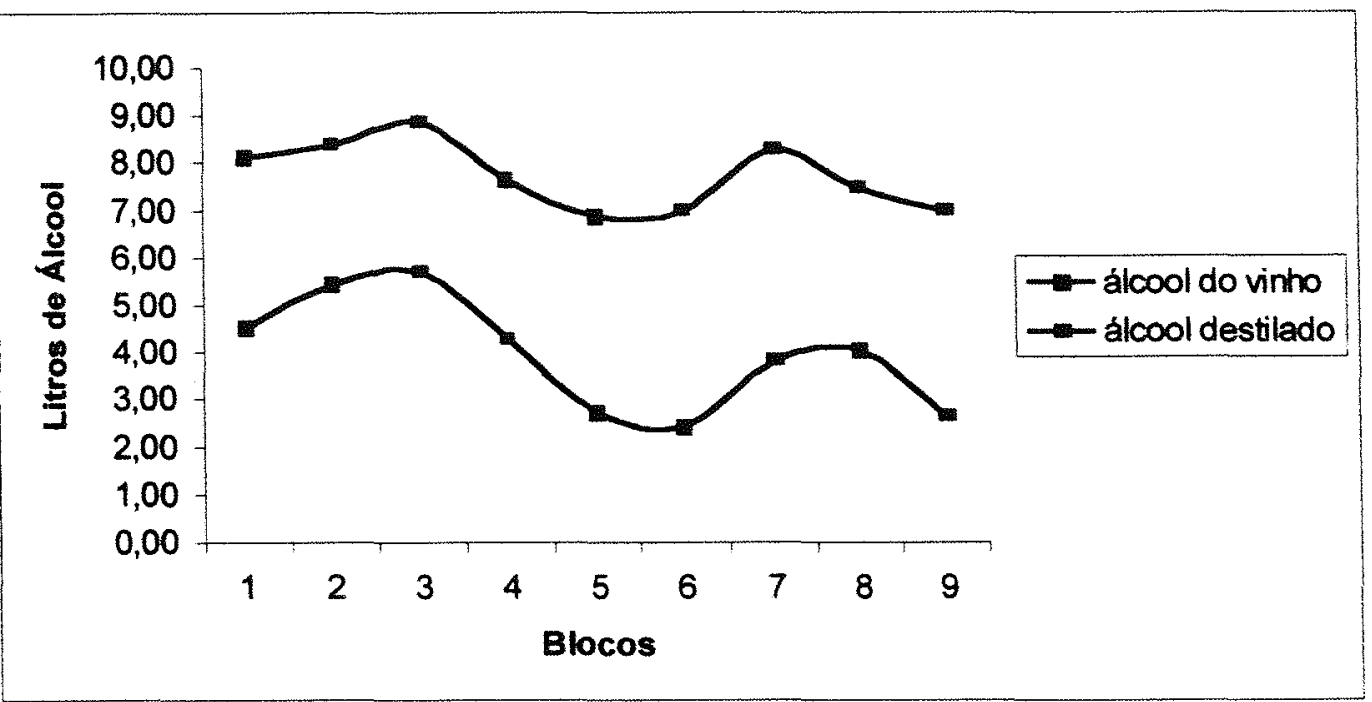

Figura 1 - Quantidade de etanol nos vinhos e nos destilados - Tratamento A.M.

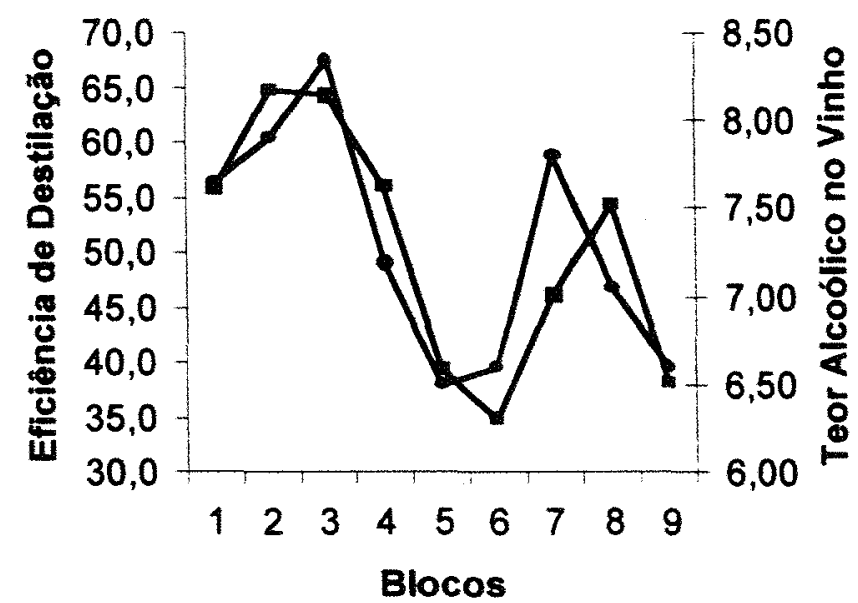

Figura 2 - Eficiência de destilação segundo o líquido gerador - Tratamento A.M. 
5.2.2. Processo da dupla destilação.

\subsubsection{Obtenção do flegma.}

Os resultados obtidos na condução da destilação para a obtenção dos flegmas, respectivos a cada bloco de amostragem, são ilustrados na tabela 3 .

Tabela 3 - Parâmetros de destilação do Tratamento A.B.

\begin{tabular}{|c|c|c|c|c|c|c|}
\hline Bloco & $\begin{array}{c}\text { Teor } \\
\text { alcoólico da } \\
\text { mistura }^{\mathrm{A}}\end{array}$ & $\begin{array}{l}\text { Alcool da } \\
\text { mistura } \\
\text { (L) }\end{array}$ & $\begin{array}{c}\text { Volume } \\
\text { de flegma } \\
\text { (L) }\end{array}$ & $\begin{array}{c}\text { Teor alcoólico } \\
\text { do flegma } \\
\left(\% \vee \cdot v^{-1}\right)\end{array}$ & $\begin{array}{l}\text { Álcool do } \\
\text { flegma } \\
\text { (L) }\end{array}$ & $\begin{array}{c}\text { Eficiência de } \\
\text { destilação } \\
(\eta)\end{array}$ \\
\hline 1 & $7,65^{*}$ & 23,56 & 112 & 20,69 & 23,17 & 98,35 \\
\hline 2 & 10,47 & 32,77 & 127 & 18,93 & 24,04 & 73,36 \\
\hline 3 & 11,15 & 34,90 & 155 & 21,04 & 32,61 & 93,45 \\
\hline 4 & 10,38 & 32,49 & 168 & 17,82 & 29,94 & 92,15 \\
\hline 5 & 9,70 & 30,36 & 160 & 17,83 & 28,53 & 93,96 \\
\hline 6 & 10,49 & 32,83 & 130 & 21,91 & 28,48 & 86,75 \\
\hline 7 & 10,29 & 32,21 & 125 & 26,69 & 33,36 & 103,59 \\
\hline 8 & 9,05 & 28,33 & 115 & 25,27 & 29,06 & 102,59 \\
\hline 9 & 8,33 & 26,07 & 116 & 22,47 & 26,07 & 99,97 \\
\hline
\end{tabular}

A = mistura de vinho + cabeça + cauda da destilação anterior

* = vinho sem reciclagem das frações cabeça e cauda

$\eta$ = Eficiência de destilação = (álcool recuperado no flegma / álcool da mistura) $\times 100$

Novamente foram obtidas teores alcoólicos no destilado, proporcionais às do líquido gerador, conforme ilustrado na figura 3 . 


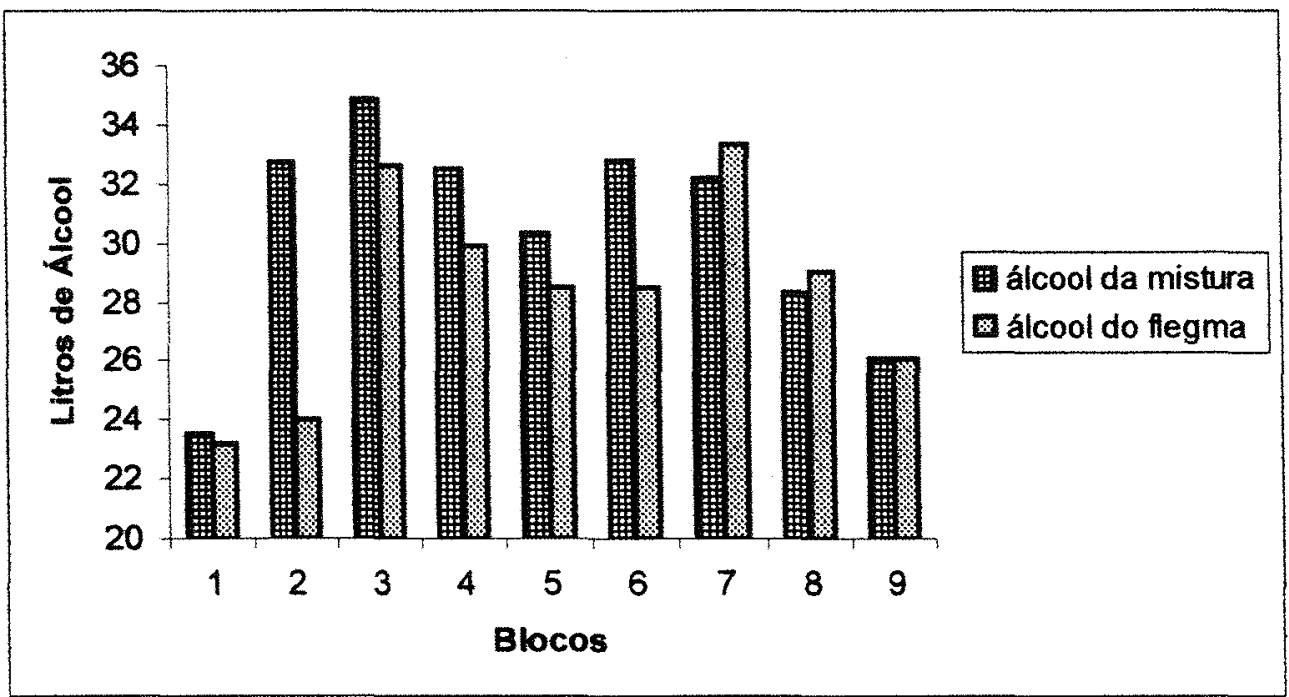

Figura 3 - Quantidade de etanol nos vinhos e nos destilados - Tratamento A.B.

O maior volume do álcool recuperado no flegma em relação ao álcool da mistura que o originou pode ser atribuída a erros de medida de volume, na ocasião do abastecimento dos alambiques.

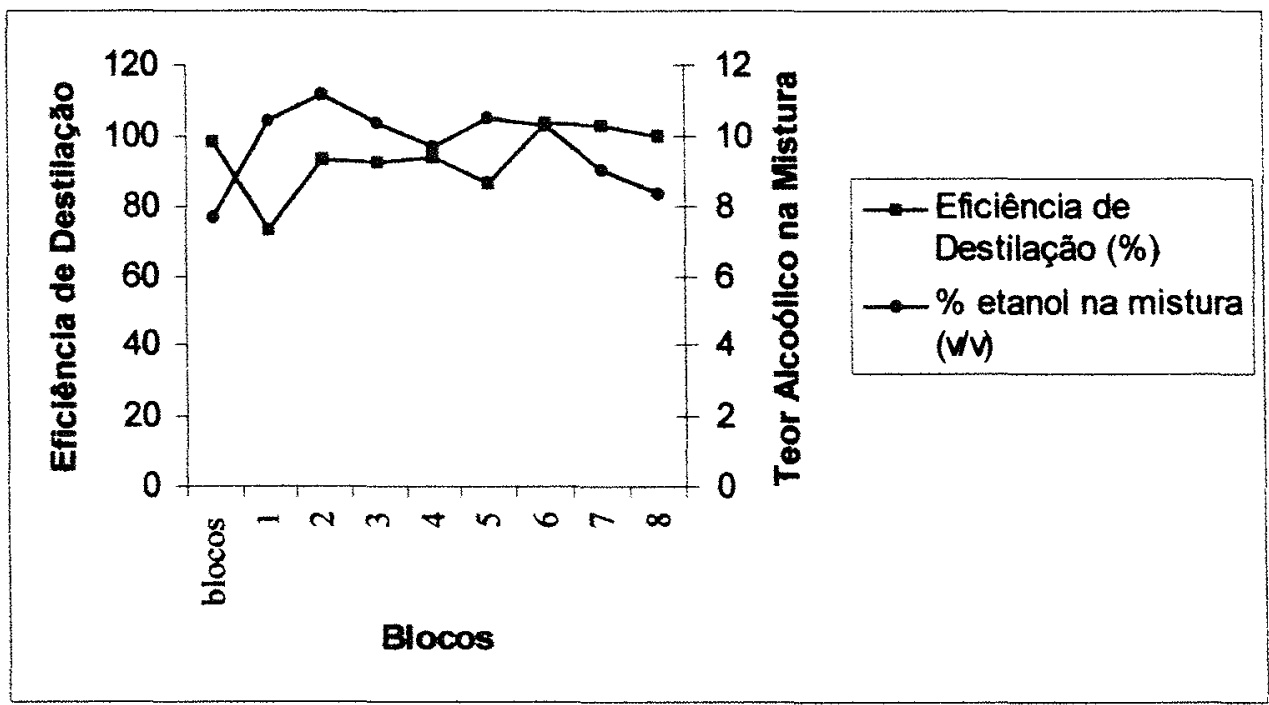

Figura 4 - Eficiência de destilação segundo o liquido gerador - Tratamento A.B. 


\subsubsection{Obtenção do destilado final.}

Os resultados obtidos sobre a condução da destilação para obtenção do destilado final são ilustrados na tabela 4.

Tabela 4 - Quantidades de produto e de etanol - Tratamento A.B.

\begin{tabular}{ccccccccc}
\hline & \multicolumn{2}{c}{ Flegma } & \multicolumn{2}{c}{ Cabeça } & \multicolumn{2}{c}{ Coração } & \multicolumn{2}{c}{ Cauda } \\
& Volume & $\%$ álcool & Volume & $\%$ álcool & Volume & $\%$ álcool & Volume & $\%$ álcool \\
Bloco & $(\mathrm{L})$ & $\left({\left.\mathrm{v} . \mathrm{v}^{-1}\right)}^{-1}\right.$ & $(\mathrm{L})$ & $\left(\mathrm{v} . \mathrm{v}^{-1}\right)$ & $(\mathrm{L})$ & $\left({\left.\mathrm{v} . \mathrm{v}^{-1}\right)}^{-1}\right.$ & $(\mathrm{L})$ & $\left(\mathrm{v.v}^{-1}\right)$ \\
\hline 1 & 112 & 20,7 & 2 & 70,7 & 12 & 67,3 & 40 & 24,9 \\
2 & 127 & 18,9 & 2 & 72,7 & 6,5 & 65,0 & 60 & 20,8 \\
3 & 155 & 21,0 & 2 & 70,2 & 7,5 & 65,8 & 60 & 21,7 \\
4 & 168 & 17,8 & 2 & 65,3 & 3,7 & 64,5 & 61 & 21,0 \\
5 & 160 & 17,8 & 2 & 67,0 & 3,25 & 66,8 & 58 & 26,1 \\
6 & 130 & 21,9 & 1,5 & 71,8 & 17 & 67,0 & 33 & 28,5 \\
7 & 125 & 26,7 & 1,5 & 74,6 & 24 & 67,2 & 34 & 22,3 \\
8 & 115 & 25,3 & 1,5 & 71,7 & 23 & 65,1 & 32 & 20,5 \\
9 & 116 & 22,5 & 1,5 & 71,2 & 18 & 67,1 & 35 & 21,2 \\
\hline
\end{tabular}

Observa-se que houve diferenças tanto no volume como no grau alcoólico da fração "cabeças". Esta variação no teor alcoólico foi devida à atenuação abrupta do grau alcoólico frente a velocidade de destilação, obtendo-se baixo volume de destilado (de 1,5\% a 2,0\% em relação ao volume de "flegma" contido na caldeira do aparelho de destilação), o que proporcionou certa dificuldade na determinação, de acordo com a metodologia proposta. 
Supõe-se que trabalhando com destiladores maiores, e/ou menor velocidade de destilação, possa-se determinar esta fração com maior acuidade.

Na fração "coração", houve maior uniformidade no tocante ao grau alcoólico, fixado anteriormente em torno de $65 \% \mathrm{v} / \mathrm{v}$, isto porque nesta etapa da destilação a variação no teor alcoólico era menos brusca, facilitando as tomadas de medida; as diferenças encontradas nos volumes provavelmente se deveram a dois fatores primordiais: diferença no teor alcoólico do líquido gerador ( flegma ),tendência observada na figura 5 e comprovada pela figura 6 , e dificuldade no controle da velocidade de destilação. 


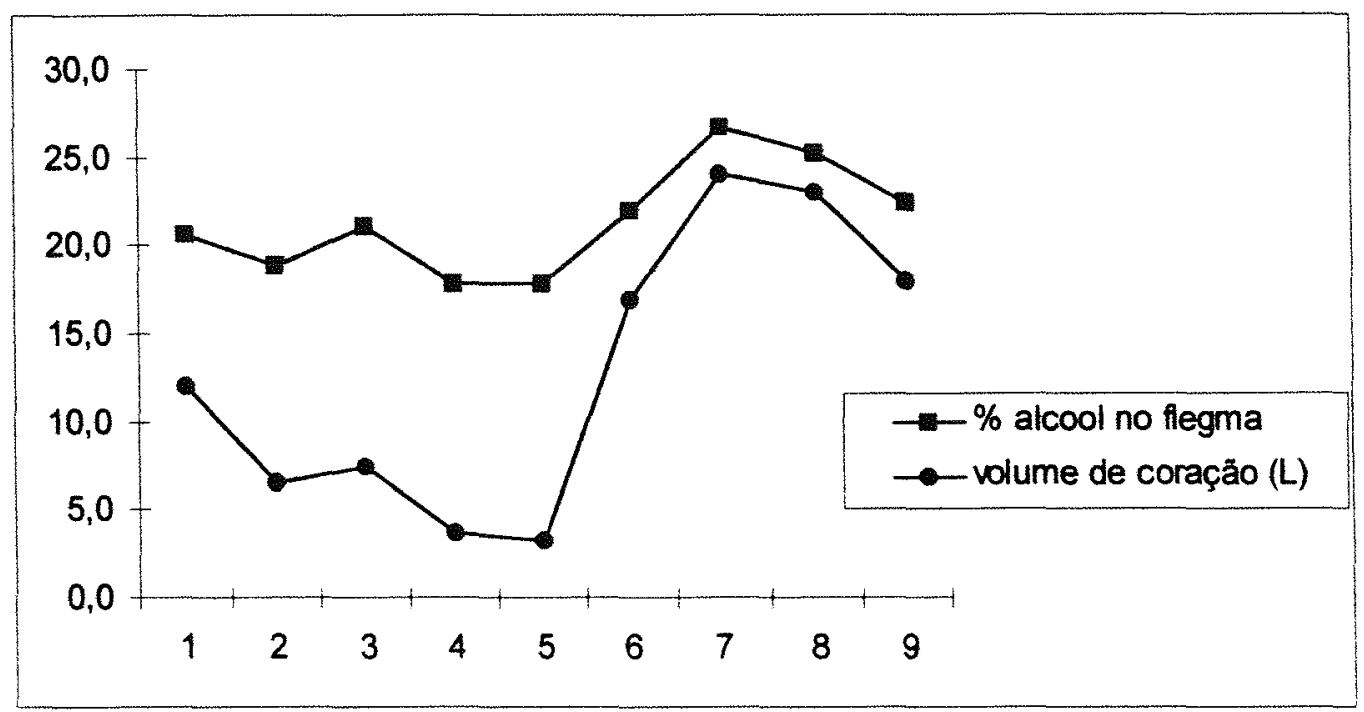

Figura 5 - Teores alcoólicos dos flegmas e volumes de coração obtidos - Tratamento A.B.

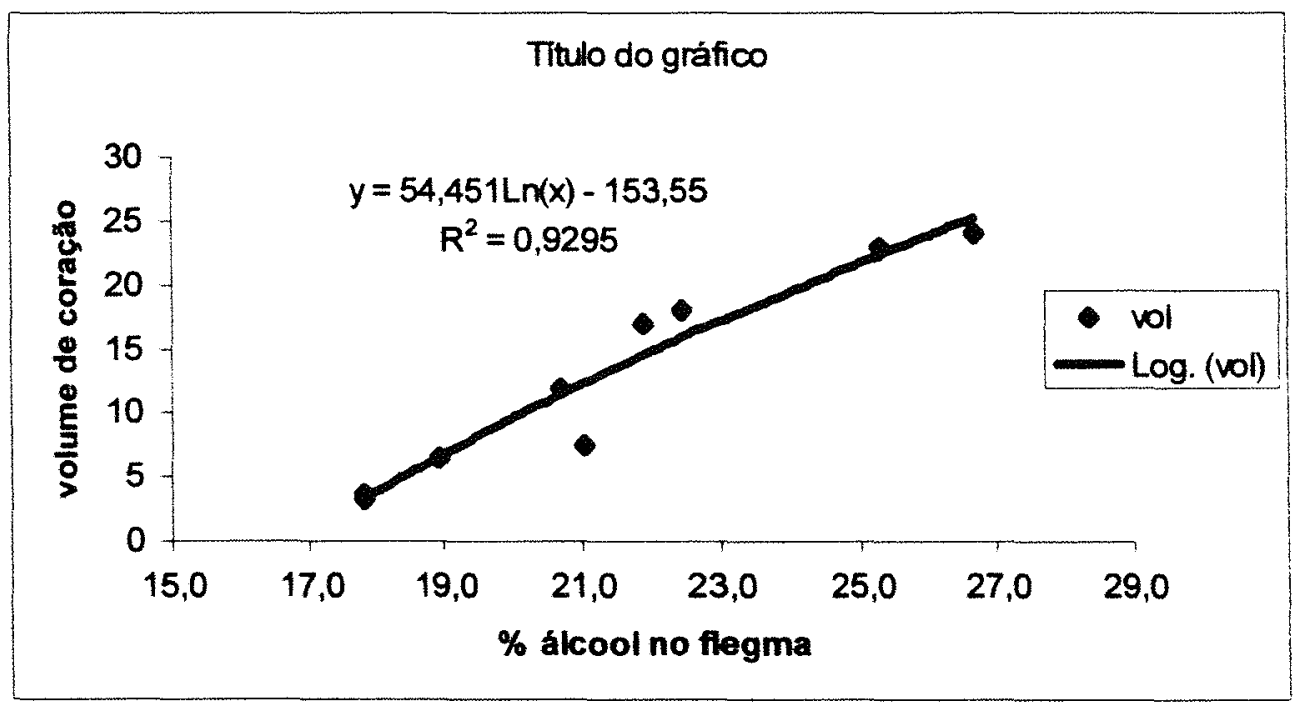

Figura 6 - Volume de coração obtido em função do teor alcoólico do líquido gerador (flegma) 


\subsection{Análise comparativa entre as aguardentes.}

As aguardentes já padronizadas provenientes dos tratamentos A.M. e A.B. foram submetidas às análises físico-químicas, sendo que os resultados médios obtidos constam na tabela 5 . Os dados individuais de cada tratamento bloco a bloco constam do apêndice 1 . Tabela 5 - Análise físico-química entre os tratamentos (médias de 9 repetições)

Tratamentos Componentes A M A B

Densidade real $\left(20 / 4^{\circ} \mathrm{C}\right)$

$0,9469 \quad 0,9470$

Grau alcóolico real \% $\left({\left.\mathrm{v} . \mathrm{v}^{-1}\right)}^{-1}\right.$ $40,71 \quad 40,66$

Acidez Total (mgCH ${ }_{3} \mathrm{COOH} .100 \mathrm{ml}^{-1}$ ETOH $100 \%$ )

$43,95 \quad 17,95^{* *}$

Acidez volátil (mgCH ${ }_{3} \mathrm{COOH} .100 \mathrm{ml}^{-1}$ ETOH $\left.100 \%\right)$

$42,60 \quad 17,00^{* *}$

Acidez fixa $\left(\mathrm{mgCH}_{3} \mathrm{COOH} .100 \mathrm{ml}^{-1}\right.$ ETOH $\left.100 \%\right)$

$1,35 \quad 0,92^{* *}$

Furfurol (mg.100 $\mathrm{ml}^{-1}$ ETOH 100\%)

$0,00 \quad 0,00$

Cobre (mg. $\left.L^{-1}\right)$

$2,67 \quad 0,32^{* *}$

Extrato seco (g.L $\left.\mathrm{L}^{-1}\right)$

$0,03 \quad 0,03$

Aldeídos (mg aldeído acético. $100 \mathrm{ml}^{-1}$ ETOH 100\%)

$21,11 \quad 15,80^{*}$

Acetona (mg.100 $\mathrm{ml}^{-1}$ ETOH $100 \%$ )

$1,81 \quad 1,68$

Ésteres (mg.100 $\mathrm{ml}^{-1}$ ETOH 100\%)

$20,269,74^{* *}$

Metanol (mg.100 $\mathrm{ml}^{-1}$ ETOH 100\%)

$17,36 \quad 14,13$

n-Propanol (mg.100 $\mathrm{ml}^{-1}$ ETOH 100\%)

$27,82 \quad 25,20$

i-Butanol (mg.100 $\mathrm{ml}^{-1}$ ETOH 100\%)

$81,17 \quad 69,34$

n-Butanol (mg.100 $\mathrm{ml}^{-1}$ ETOH 100\%)

$0,51 \quad 0,26$

i-Amílico (mg.100 $\mathrm{ml}^{-1}$ ETOH 100\%)

$287,91 \quad 254,28$

n-Amílico (mg.100 $\mathrm{ml}^{-1}$ ETOH 100\%)

$0,00 \quad 0,00$

Álcoois superiores (mg.100 $\mathrm{ml}^{-1}$ ETOH 100\%)

$397,17 \quad 349,33$

Compostos secundários (mg.100 $\mathrm{ml}^{-1}$ ETOH 100\%)

$481,15 \quad 391,72$

* $\mathrm{e}^{* *}=$ significativo a $5 \%$ e $1 \%$ de probabilidade no teste $\mathrm{F}$. 


\subsubsection{Acidez total}

A bidestilação influiu nos teores de acidez total da aguardente, obtendo-se com este tratamento os menores valores $(17,95$ $\mathrm{mgCH}_{3} \mathrm{COOHx} 100 \mathrm{~mL}^{-1}$ EtOH $100 \%$ ) comparados aos do tratamento A.M. $\left(43,95 \mathrm{mgCH}_{3} \mathrm{COOHx} 100 \mathrm{~mL}^{-1}\right.$ EtOH $\left.100 \%\right)$. Os resultados individuais das amostras constam da figura 7.

A acidez é representada por compostos solúveis principalmente em água e com elevado ponto de ebulição, que destilam a partir da metade final do coração e na totalidade da cauda (Léauté, 1990). Quando se destilou o flegma, cujo teor alcoólico médio era de 21,4\% em volume a $20^{\circ} \mathrm{C}$, ao final da fração "coração" o teor alcoólico daquele líquido gerador ainda era significativo, desta forma, os componentes que conferem acidez ao destilado, situaram-se em maior proporção na fração "cauda", conferindo assim à aguardente bidestilada baixos teores de acidez, fato que não ocorreu com a aguardente monodestilada submetida a uma única destilação e originada de líquido gerador de baixo teor alcoólico $(7,3 \% \mathrm{v} / \mathrm{v})$. Como esses ácidos apresentam baixa volatilidade em líquido gerador de elevado teor alcoólico, como aquele do qual resultou a fração "coração", somente quando ele se encontrar mais esgotado em álcool é que tais ácidos irão se volatilizar em maior quantidade, em cuja etapa da destilação resultará a última fração, ou seja, a "cauda". 


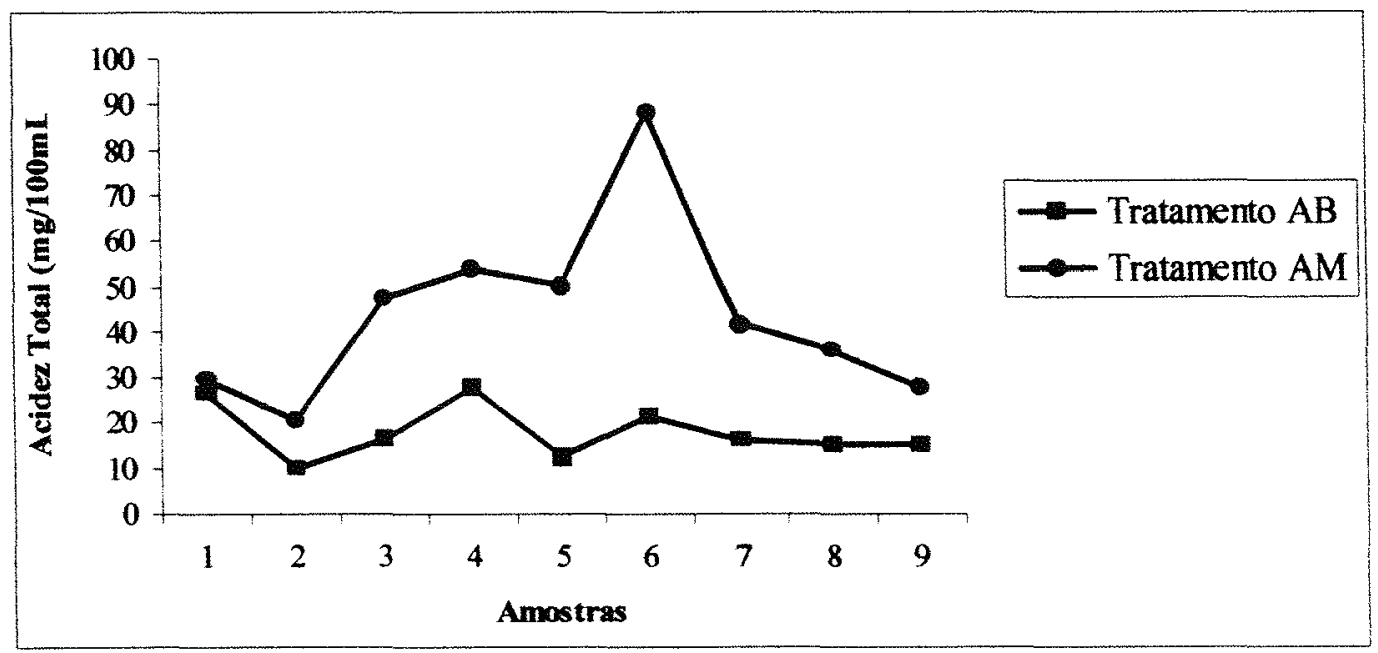

Figura 7 - Acidez total das amostras

\subsubsection{Densidade e grau alcoólico.}

Embora tenha havido padronização, as diferenças na densidade e grau alcoólico encontradas entre as amostras estão dentro do proposto na metodologia, $40 \pm 1 \%$ em volume a $20{ }^{\circ} \mathrm{C}$. Tais diferenças são decorrentes de imprecisões no decorrer da pesagem e diluição das amostras. As figuras 8 e 9 mostram estas diferenças. 


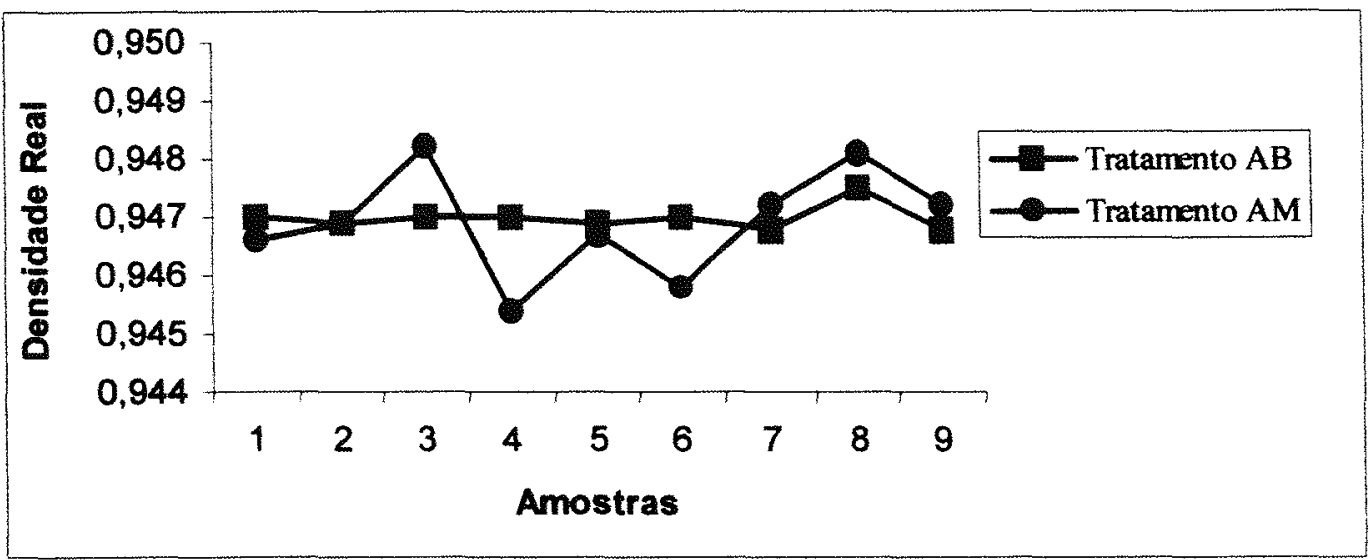

Figura 8 - Densidade das amostras.

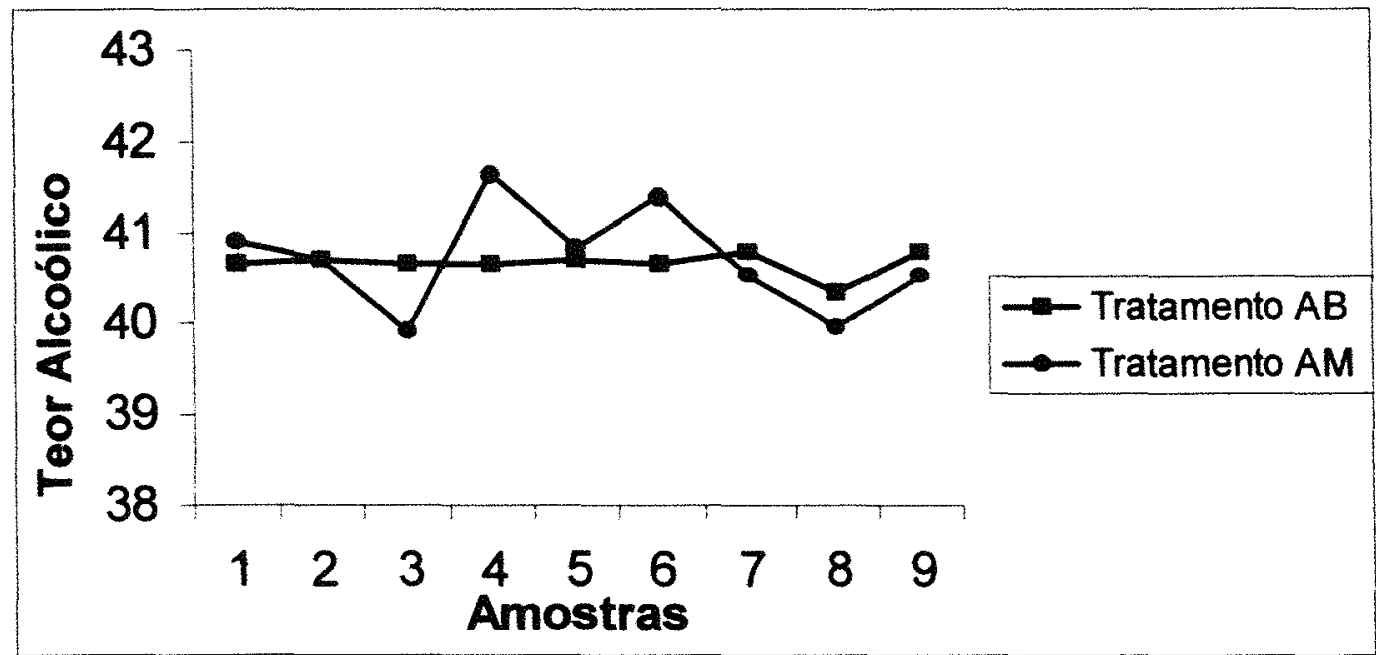

Figura 9 - Teores alcoólicos das amostras.

\subsubsection{Furfural.}

Segundo Chaves \& Póvoa (1992), o furfural é proveniente da pirogenização de matéria orgânica presente nos vinhos, no decorrer da destilação. 
A pirogenação da matéria orgânica presente no vinho ocorre principalmente quando este é aquecido a "fogo direto", ocasião em que podem ocorrer superaquecimentos isolados na superfície do alambique e promover o aparecimento do furfural( Valsechi,1970).

Como descrito anteriormente, o aquecimento do vinho neste experimento se deu de forma indireta; além do mais, sendo tal vinho resultante de uma centrifugação, o mesmo se encontrava praticamente isento de material orgânico em suspensão. Consequentemente as aguardentes resultantes da destilação destes vinhos não acusaram presença de furfural.

\subsubsection{Cobre.}

Houve diferença significativa $(p \leq 0,01)$ entre os teores de cobre dos tratamentos, observando-se os menores valores para o tratamento A.B.

De acordo com Lucena (1959), o cobre presente nas aguardentes é proveniente da dissolução do "azinhavre" (carbonato básico de cobre solúvel em ácido) que se forma no interior do alambique e, principalmente nas partes internas da serpentina da resfriadeira.

Desta forma, quando da destilação do flegma, conforme visto anteriormente, os vapores hidroalcoólicos ácidos destilam principalmente na fração "cauda", e como foi a fração "coração" que deu origem à aguardente bidestilada, esta apresentou teores de cobre sempre inferiores à unidade e, em alguns casos, nulos. Já a aguardente monodestilada apresentou valores superiores, porém dentro dos limites fixados pela Legislação. 
Nas condições em que foi montado o experimento não foi possível estabelecer correlação entre teor de cobre e acidez, conforme ilustrado nas figuras 10 e 11 .

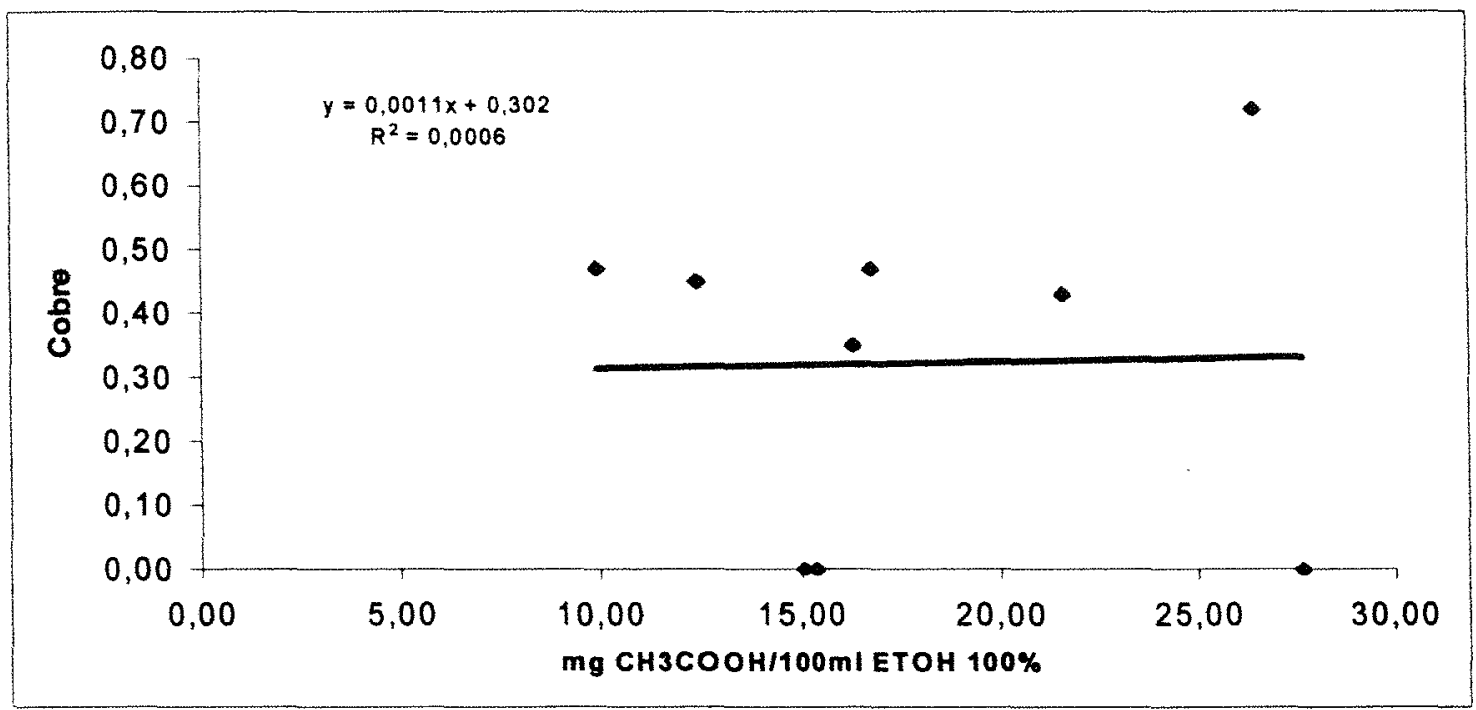

Figura 10 - Cobre em função da acidez total no tratamento A.B. 


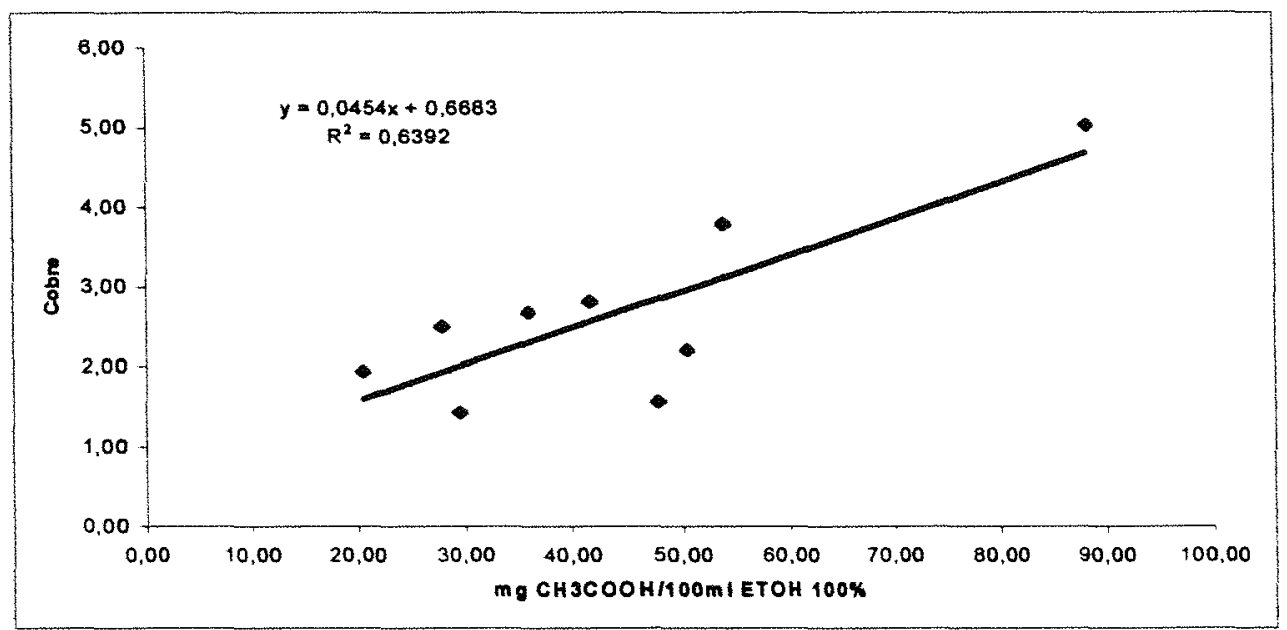

Figura 11 - Cobre em função da acidez total no tratamento A.M.

Isto pode ter sido devido a fatores não controlados tais como, quantidade de azinhavre presente no destilador, assepsia do aparelho, tempo de formação do azinhavre, intervalo entre as diversas destilações, velocidade de destilação, temperatura de destilação, dentre outros; mostrando não ser apenas a acidez do destilado responsável pelo conteúdo de cobre nas aguardentes, mostrando a necessidade de estudos específicos que estabeleçam tal correlação.

Outra provável explicação isto para a não ocorrência de correlação seria dada em função dos baixos teores de acidez existentés nos destilados. 


\subsubsection{Aldeídos.}

São componentes do aroma e sabor das aguardentes, apresentando alta solubilidade em etanol e baixo ponto de ebulição. Durante a destilação concentram-se nas frações de elevado teor alcoólico.

Os teores de aldeído obtidos em ambos os tratamentos não diferiram entre sí ao nível de significância de 5\%, mostrando que nas condições do experimento, a bidestilação não surtiu efeito esperado de redução de aldeídos, que teoricamente ficariam retidos na fração "cabeças".

Tal se deve ao fato de que o aldeído acético é extremamente volátil em diferentes teores alcoólicos dos líquidos geradores segundo Meloni, citado por Novaes (1994). Contudo para aguardente bidestilada foi observada uma tendência para valores menores. Isto se deveu provavelmente, ao fato de se eliminar a fração "cabeça", o que não era efetuado para aguardente monodestilada.

Embora não comprovados analiticamente estes teores também podem ter sido decorrentes da variação nos teores de aldeídos dos vinhos, uma vez que o teor deste componente no destilado é reflexo da sua concentração no vinho ( Ribeiro, 1997 ).

\subsection{6. Ésteres.}

São componentes de alta solubilidade em álcool e baixo ponto de ebulição. Desta forma, destilam principalmente nas frações de teor alcoólico elevado, concentrando-se pois nas frações "cabeça" e início da 
fração "coração". Logo seu teor na aguardente bidestilada foi significativamente inferior ao da aguardente monodestilada, visto ambas serem elas originadas a partir de líquidos geradores com diferentes teores alcoólicos, além do fato que na aguardente bidestilada foi efetuada a separação da fração “cabeças”, como mostra a figura 12.

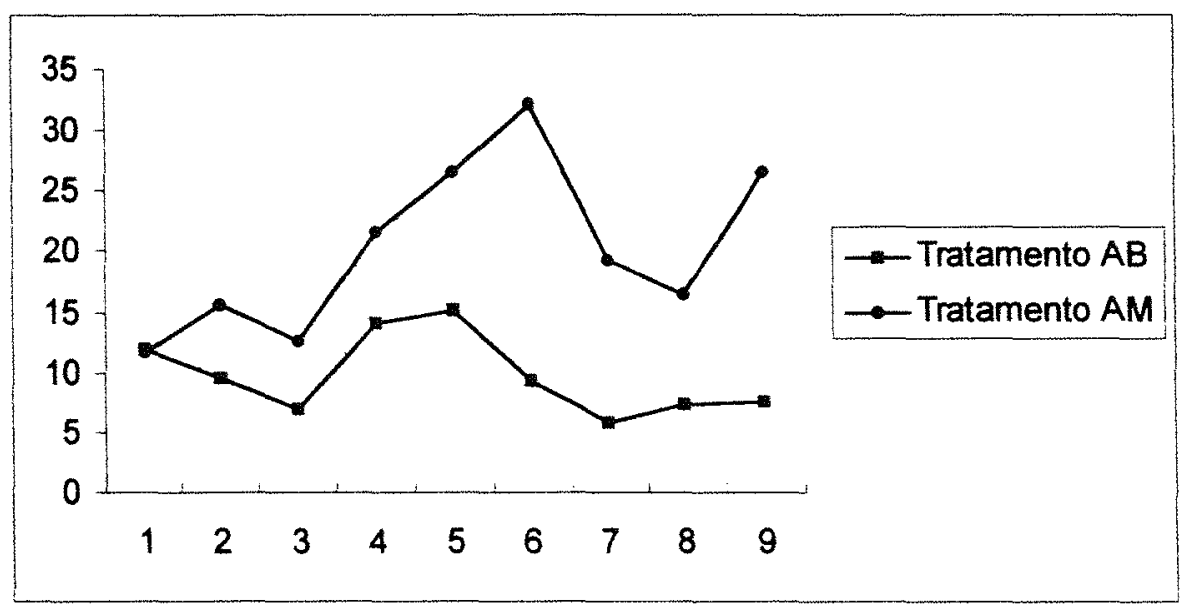

Figura 12 - Teores de ésteres das amostras.

\subsection{7. Álcoois superiores.}

São componentes com elevado ponto de ebulição, solúveis em álcool e parcialmente solúveis em água. Durante a destilação fazem-se presentes principalmente na fração "cabeça", assim como na fração "coração", devido ao fato de que, em função daquela solubilidade, serem bastante voláteis em misturas de baixo teor alcoólico, como é o caso do vinho e do flegma

Desta forma, são encontrados tanto na aguardente bidestilada como na aguardente monodestilada, embora nesta seu teor tenha sido mais elevado, já que, na produção da aguardente bidestilada efetua-se a 
separação da fração "cabeças", aliado ao fato de que o teor alcoólico médio do flegma era cerca de três vezes superior àquele do vinho, ajudando assim na maior retenção dos álcoois superiores nesse líquido gerador.

A figura 13 mostra essa diferença, embora não seja estatisticamente significativa.

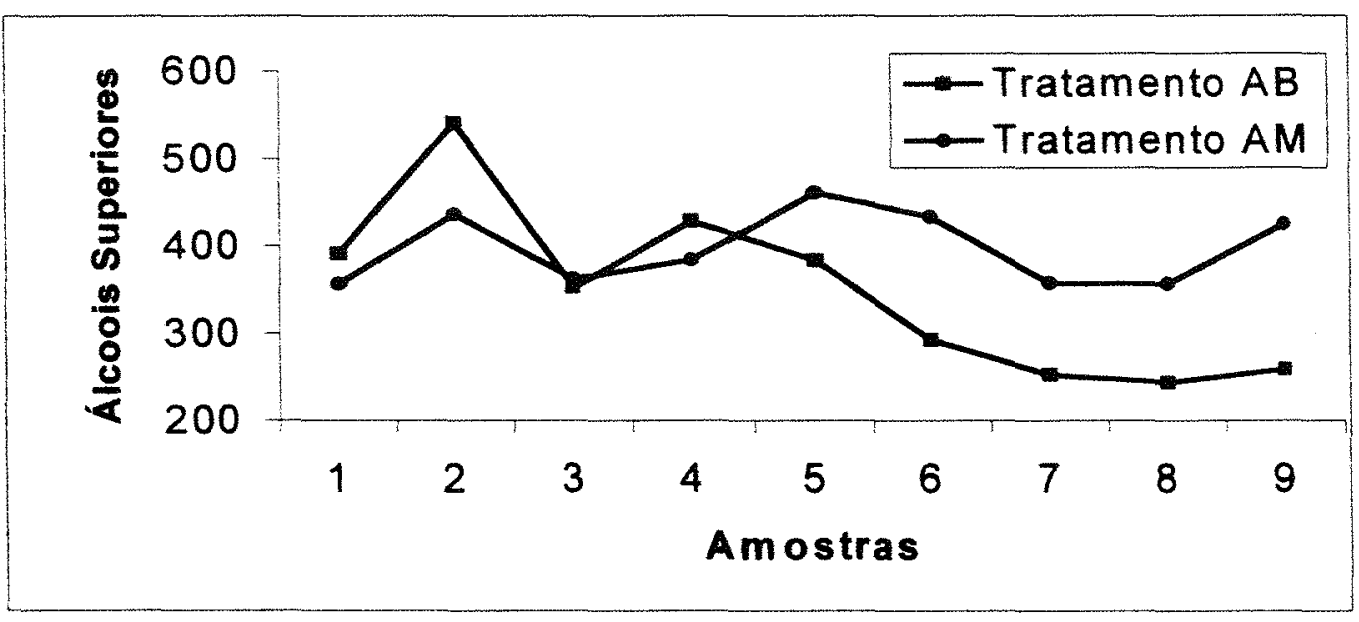

Figura 13 - Teores de álcoois superiores das amostras.

\subsubsection{Metanol.}

Tem comportamento semelhante ao dos álcoois superiores, sendo solúvel em álcool e parcialmente solúvel em água.

Desse modo, não foram observadas diferenças significativas nos teores desse componente para as aguardentes provenientes de ambos os tratamentos. 
Entretanto na aguardente bidestilada observou-se uma tendência para valores inferiores do mesmo, provavelmente devido ao fato de que neste tratamento foi eliminada a fração "cabeça", o que não foi efetuado para aguardente monodestilada.

Referida tendência pode ser observada na figura 14.

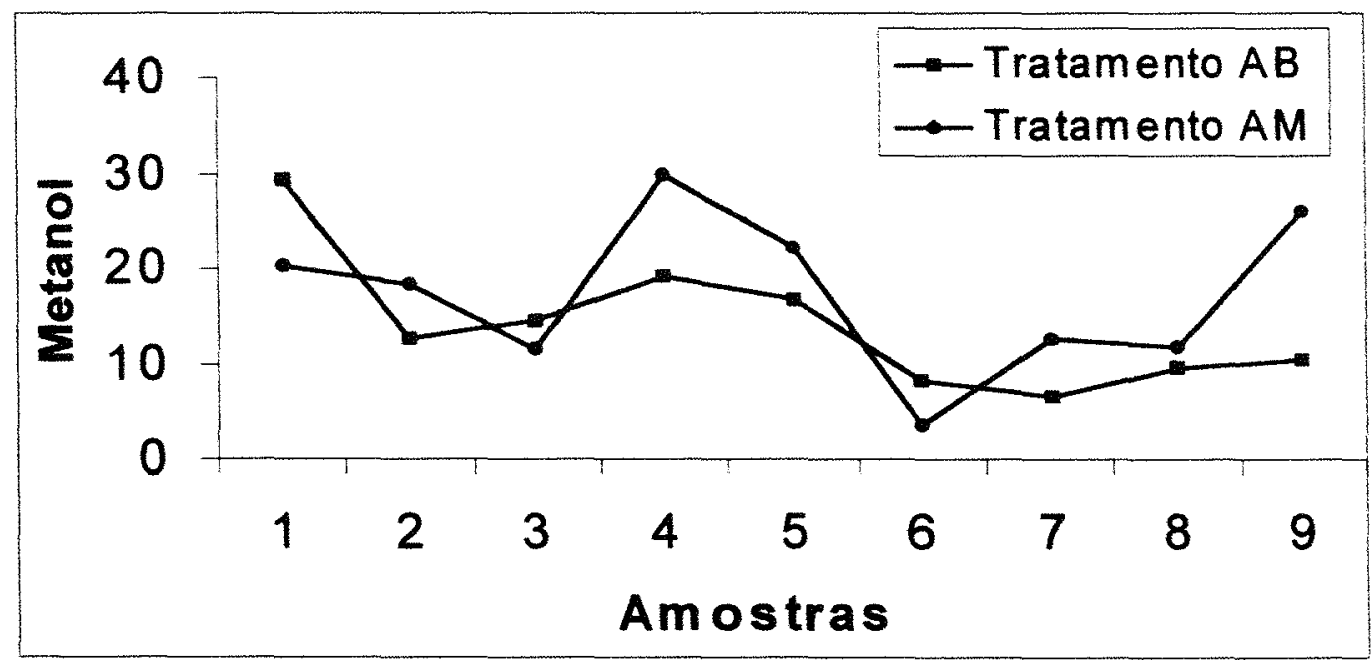

Figura 14 - Teores de metanol nas amostras. 


\subsection{Análise sensorial.}

\subsubsection{Teste triangular de preferência}

Quando se compararam amostras do mesmo tratamento ficou evidenciado que houve uniformidade nas condições de destilação, independente do tratamento a que foram submetidas, pois os resultados obtidos não se mostraram significativos.

A comparação de amostras de tratamentos diferentes mostrou que as técnicas de destilação causaram diferenças significativas nas amostras submetidas a estes tratamentos, mostrando que quando se procedeu a bidestilação obteve-se um produto diferente do convencional.

Os resultados numéricos de ambos os casos estão dispostos nas tabelas 6 e 7 .

Tabela 6 -Teste triangular de diferença entre os diferentes tratamentos

\begin{tabular}{lccc}
\hline Amostras comparadas & $\mathrm{AM} \times \mathrm{AB}$ & $\mathrm{AM} \times \mathrm{AB}$ & $\mathrm{AM} \times \mathrm{AB}$ \\
\hline $\mathrm{N}^{\circ}$ de julgamentos & 22 & 22 & 24 \\
$\mathrm{~N}^{\mathrm{o}}$ de acertos & 13 & 15 & 15 \\
$\mathrm{~N}^{\mathrm{o}}$ de erros & 9 & 7 & 9 \\
Nível de significancia & 0,05 & 0,001 & $0,01 / 0,001$ \\
\hline
\end{tabular}


Tabela 7 - Teste triangular de diferença entre as amostras do mesmo tratamento

\begin{tabular}{lll}
\hline Amostras comparadas & AM x AM & AB x AB \\
\hline $\mathrm{N}^{0}$ de julgamentos & 24 & 24 \\
$\mathrm{~N}^{\circ}$ de acertos & 11 & 11 \\
$\mathrm{~N}^{\circ}$ de erros & 13 & 13 \\
Nível de significancia & $\mathrm{ns}$ & $\mathrm{ns}$ \\
\hline $\mathbf{n s}=\mathbf{n a ̃ o}$ significatigo $(\mathbf{p} \leq \mathbf{0 , 0 5})$
\end{tabular}

\subsubsection{Teste pareado de preferência.}

Apesar de haver diferença significativa, verificada pelo teste triangular, entre as amostras submetidas aos diferentes tratamentos, os degustadores não manifestaram preferência por uma ou outra aguardente ao nível de $5 \%$ de probabilidade, verificada pelo Teste Pareado de Preferência, cujos dados encontram-se dispostos na tabela 8

Tabela 8 - Teste Pareado de Preferência

\begin{tabular}{lccc}
\hline Amostras comparadas & $\mathrm{AM} \times \mathrm{AB}$ & $\mathrm{AM} \times \mathrm{AB}$ & $\mathrm{AM} \times \mathrm{AB}$ \\
\hline $\mathrm{N}^{\circ}$ de julgamentos corretos & 13 & 15 & 15 \\
Preferência-AB & 7 & 9 & 5 \\
Preferência-AM & 6 & 6 & 10 \\
Nível significância & $\mathrm{ns}$ & $\mathrm{ns}$ & $\mathrm{ns}$ \\
\hline
\end{tabular}




\section{CONCLUSÕES.}

Nas condições em que foi realizado o ensaio, pode-se concluir que o processo de dupla destilação tem efeito positivo sobre os parâmetros tecnológicos avaliados, destacando-se a significativa redução nos teores de acidez acética e de cobre.

$\mathrm{O}$ processo de dupla destilação produziu ainda uma bebida com características sensoriais distintas da convencional não sendo, porém, definida preferência pela aguardente originada por ambos os processos, uma vez que se trata de parâmetro estritamente pessoal. 


\section{REFERÊNCIAS BIBLIOGRÁFICAS}

ALMEIDA, J.R. de. Álcool e destilaria. Piracicaba: Ed. Nathanael dos Santos, 1940. p.75 - 81.

ALMEIDA, J. R. de. Destilação dos vinhos para obtenção das aguardentes. Revista Tecnologia das Bebidas, v.5, n.I, p.7-9, 1952.

AMERINE, M.A.; BERG, H.W.; CRUESS, W.V. The tecnology of wine making. 3. ed. Westport; AVI Publ, 1972. 802 p.

BAUDOIN, M.A. Essais comparatifs de quelques eaux-de-vies faits au laboratoire de chimie de cognacs. Bulettin de l'Association du Chimique. v.22, n.12, p.1905.

BOZA, Y.E.A.G. Influência da condução da destilação sobre a composição e a qualidade sensorial da aguardente de cana. Piracicaba, 1996. $140 \mathrm{p}$. Dissertação (Mestrado)- Escola Superior de Agricultura "Luiz de Queiroz", Universidade de São Paulo. 
BRASIL. Ministério da Agricultura. Secretaria Nacional de Defesa Agropecuária. Portaria 371. Complementação de padrões de identidade e qualidade. Diário Oficial da União de 18/09/1974. Brasília, p.11-2

BRASIL, Ministério da Agricultura e Reforma Agrária. 1994. Lei nº 8.918, Diário Oficial da União, 05 de setembro de 1997. N 171, Seção II, Parte I. p. 19549-61.

CASTILHO, R. Conhaques: o santo da casa faz milagres. Playboy v.5, n.4, p.54-57, 1991.

CHAMINADE, R. La production et le commerce des eaux-de-vie et de vin. Paris: J.B. Baillière \& Fils, 1930. p.33-34.

CHAVES, J.B.P.; PÓVOA,M.E.B. A Qualidade da aguardente de cana-deaçúcar. In: MUTTON,M.J.R.; MUTTON,M.A. Aguardente de cana produção e qualidade. Jaboticabal: FUNEP, 1992. p. 93-132.

DIÁRIO OFICIAL, Ministério da Agricultura. Secretaria Nacional de Defesa Agropecuária, Portaria n ${ }^{\circ} 76$ de 27 de novenbro de 1986, Seção I, p.18152-9.

FARIA, J.B. A influência do cobre na qualidade da aguardente de cana ( Saccharum officinarum, L. ) São Paulo, 1989.88 p. Tese 
(Doutorado) - Faculdade de Ciências Farmacêuticas, Universidade de São Paulo.

FARIA, J.B. ; CAMPOS, M.A.P. Eliminação do cobre contaminante das aguardentes de cana-de-açúcar brasileiras. Alimentação e Nutrição, v.1, p. $117-28,1989$.

GOMES, F.P. Curso de estatística experimental. Piracicaba: Nobel,1990. Cap.3, p.18-41.

GUYMON, J. F. Hlgher alcohols in beverage brandy. Wines \& Vines, v. 53, n.I, p. 37-40, 1972.

GUTIERREZ, L.E. Tópicos de bioquímica de levedura. Piracicaba, 1989. 130 p. Tese (Livre Docência) - Escola Superior de Agricultura "Luiz de Queiroz", Universidade de São Paulo.

HASHIZUME, T. Considerações sobre ésteres nas bebidas alcoólicas. Instruções Tecnicas, n.9, p.109-21, 1976.

HIRSCH, I. Manufacture of whiskey, brandy and cordials. Newark: Sherman Eng., 1937. $183 p$.

JACINTO, A. O. Método colorimétrico do dicromato de sódio. Piracicaba, 1967.82 p. Tese ( Doutorado) - Escola Superior de Agricultura "Luiz de Queiroz", Universidade de São Paulo. 
INSTITUTO ADOLFO LUTZ. Normas analíticas do instituto Adolfo Lutz; métodos químicos e físicos para a análise de alimentos. 3 ed. São Paulo, 1985. 533p.v.1.

LAFON, R. et. al. Le cognac. Paris: J.B.Bailliere e Fils, 1964.

LIMA, U. de A. Aguardente: fabricação em pequenas destilarias. Piracicaba: FEALQ, 1999. 187 p.

LIMA, U. de A. Aguardentes. in: AQUARONE, E. et al. Alimentos e bebidas produzidos por fermentações. São Paulo: Edgar Blucher, 1983. p.79-103. (Série Biotecnologia, 5).

LIMA, U. de A. Estudos dos principais fatores que afetam os componentes do coeficiente não álcool das aguardentes de cana. Piracicaba, 1964. 141p. (Cátedra) Escola Superior de Agricultura "Luiz de Queiroz",Universidade de São Paulo.

LIMA NETO, B. dos S.; Franco, D.W. A aguardente e o controle químico de sua qualidade. Engarrafador Moderno, v.4, n.33, p.5-8, 1994.

LÉAUTÉ, R. Distillation in alambic. American Journal of Enology and Viticulture, v.41, n.1, p.90-103, 1990. 
LUCENA, V.G. de. Componentes secundários das aguardentes. Brasil Açucareiro, v.49, n.2, p.2-4, 1957.

LUCENA, V.G. O problema do cobre nas aguardentes. Brasil açucareiro, n.2, p.14-8, 1959.

MAIA, A. B. Componentes secundários da aguardente. STAB.Açúcar ,Álcool e Subprodutos, v.12, n.6, p.29-34, 1994.

MERCADO mercantil. Engarrafador Moderno. v.6, n.40, p.49, 1995.

MORI, E.E.M. Métodos sensoriais e físicos para avaliação de alimentos e bebidas: princípios e aplicação. Campinas: ITAL, 1992.

NOVAES, F.V. Noções básicas sobre a teoria da destilação. Piracicaba: ESALQ/ Depto de Ciência e Tecnologia Agroindustrial, 1994. 22p.

OLIVEIRA, A.J. Contribuição ao estudo da remoção do cobre da aguardente de cana-de-açúcar com resinas catiônicas. Piracicaba, 1970. 28p. ( Doutoramento) Escola Superior de Agricultura "Luiz de Queiroz", Universidade de São Paulo.

PACOTTET, P. Aguardientes y vinagres. Barcelona: Casa Salvat, 1922. p.205-216. 
ROSE, A.H. Alcoholic beverages. London: Academic Press, 1977. 760p.

RIBEIRO, C.A.F. Potencialidades de diferentes linhagens de levedura da espécie Saccharomyces cerevisiae na tecnologia de aguardente de cana. Piracicaba, 1997. 107 p. Dissertação (Mestrado) - Escola Superior de Agricultura "Luiz de Queiroz", Universidade de São Paulo.

RIBEIRO, C.A.F. ; HORII, J. Efeito de linhagens de levedura Saccharomyces cerevisiae na tecnologia de aguardente de cana (compact disc). In: CONGRESSO BRASILEIRO DE CIÊNCIA E TECNOLOGIA DE ALIMENTOS, 16., Rio de Janeiro, 1998. Rio de Janeiro: SBCTA, 1998.

RIBEIRO, C.A.F. ; PRADO FILHO, L.G. O cobre contaminante da aguardente de cana. Piracicaba: ESALQ/Nucleo de Apoio à Pesquisa em Microbiologia Agrícola, 1997. 24p. (NAPMA,5)

OS SEGREDOS de um bom uisque. Drinking, v.1. n.1, p.22-26, maio 1991.

SIMPSON, A.C. Manufacture of brandy. Process Biochemistry, v.6, n.12, p.25, 1971. 
SOUZA, L.G. de; LLISTÓ, A.M.S.M. Alguns componentes do coeficiente não álcool das aguardentes de cana. Determinação por cromatografia em fase gasosa. Brasil Açucareiro, v.91, n.3, p.13-16, 1978.

SUOMALAINEN, H.; NYKANEN, L. The aroma componentes produced by yeast in nitrogen- free sugar solution. Journal of the Institute of Brewing, v.72, p.469-474, 1966.

SUOMALAINEN, H.; LEHTONEN, M. The production of aroma compounds by yeast. Journal of the Institute of Brewing, v.85, n.3, p.149-156, 1979.

SUOMALAINEN, H. Yeast esterases and aroma esters in alcoholic beverages. Journal of the Institute of Brewing, v. 87, p.296-300, 1981.

STUPIELLO, J.P. Destilação do Vinho In: MUTTON,M.J.R.; MUTTON,M.A. Aguardente de cana - produção e qualidade. Jaboticabal: FUNEP, 1992. p. 93-132.

VALSECHI, O. Aguardente de cana de açúcar. Piracicaba:s.c.p. 1970. $120 p$.

WILDENRADT, H.L.; SINGLETON, V.L. The production of aldehydes as a result of polyphenolic compounds and its relation to wine aging. American Journal of Enology and Viticulture. n. 25:119-126,1984. 
WILLIAMS, P.J.; STRAUSS, C.R. A treatment of grape wine distillation heads. Journal of the Science of Food and Agriculture, v.27, n.6, p.487-498, 1976.

YOKOYA, F. Fabricação da aguardente de cana. Campinas: Fundação Tropical de Pesquisas e Tecnologia ${ }^{\star}$ André Tosello ${ }^{\infty}, 1995.283$ p. 


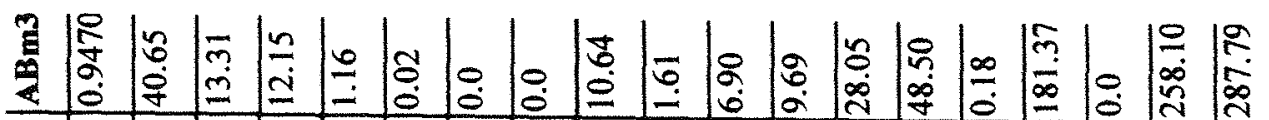

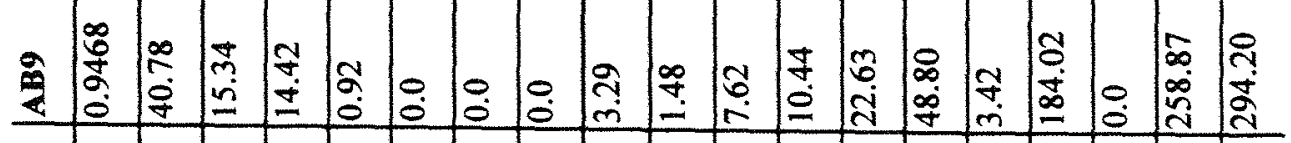

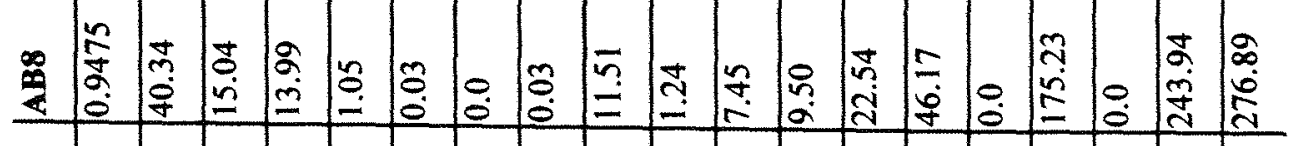

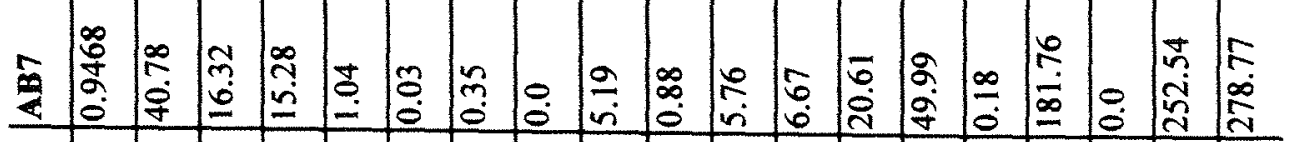

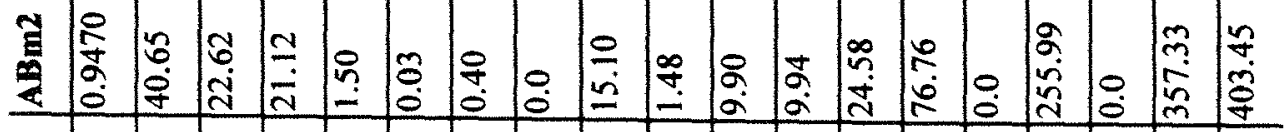

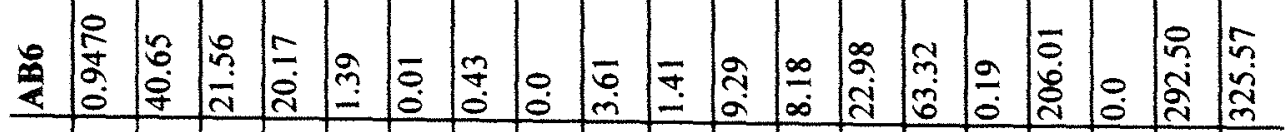

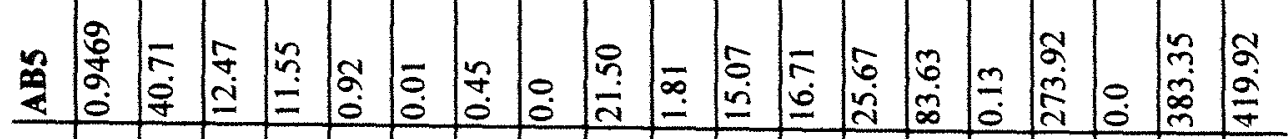

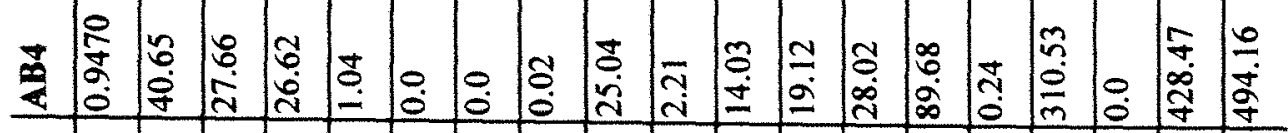

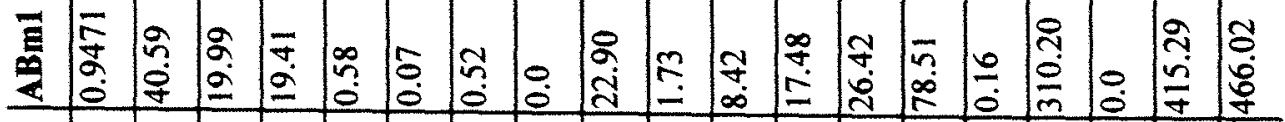

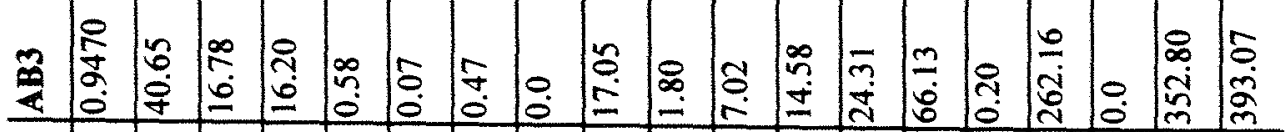

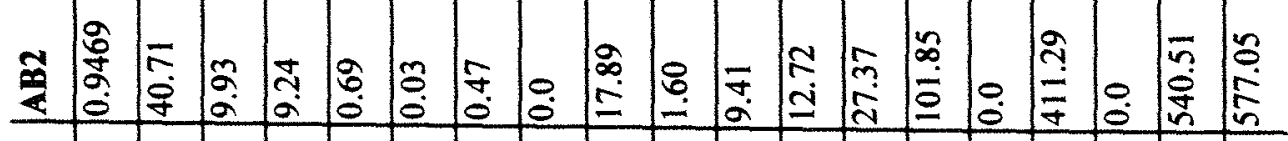

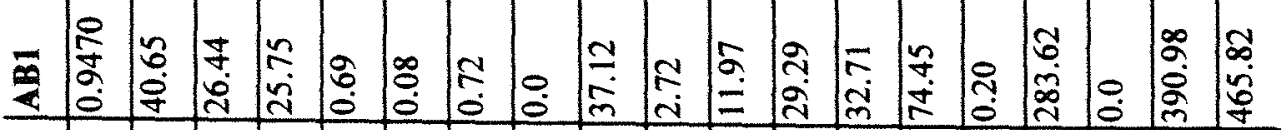

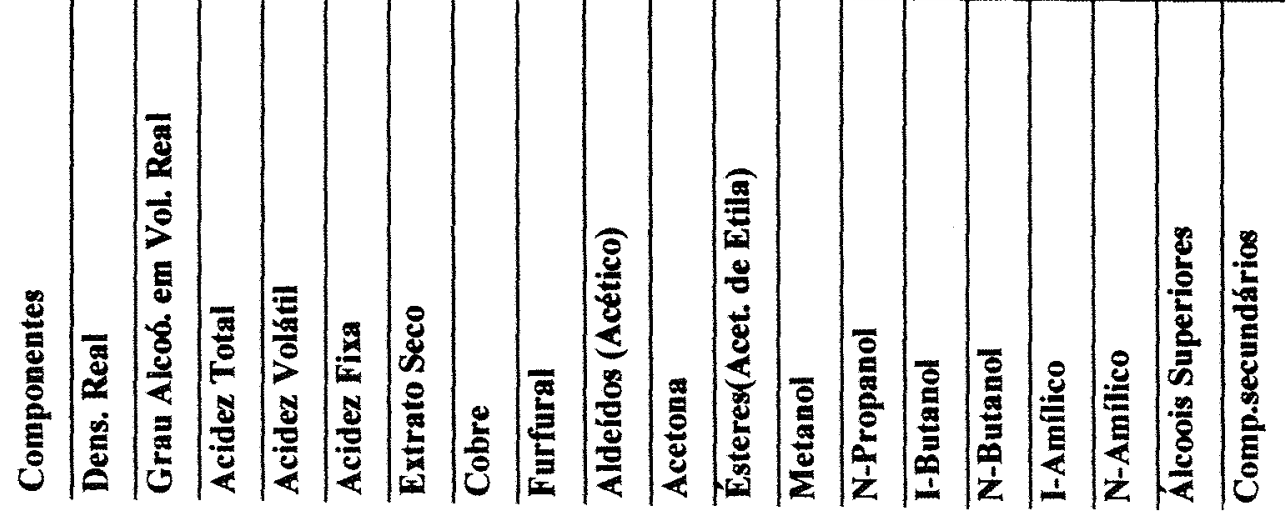




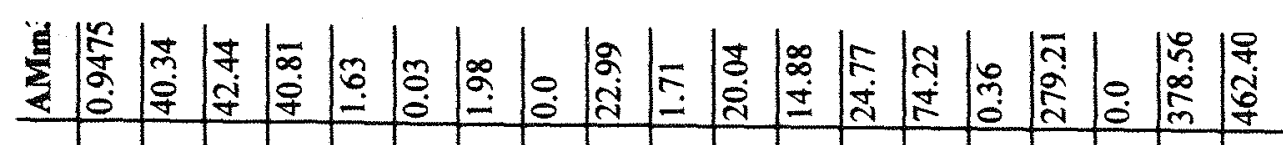

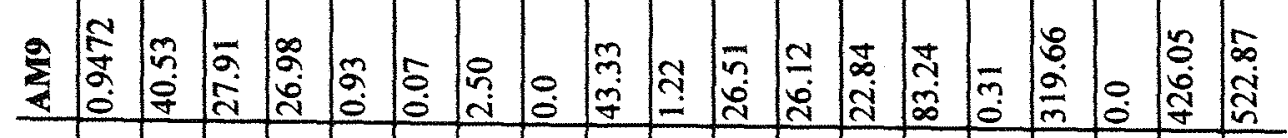

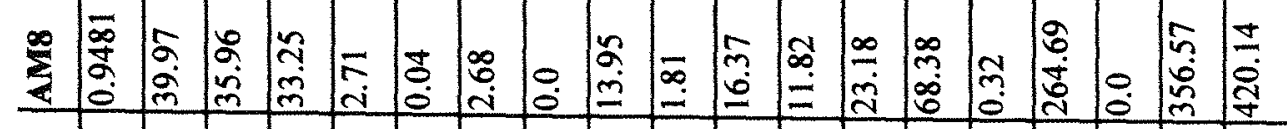

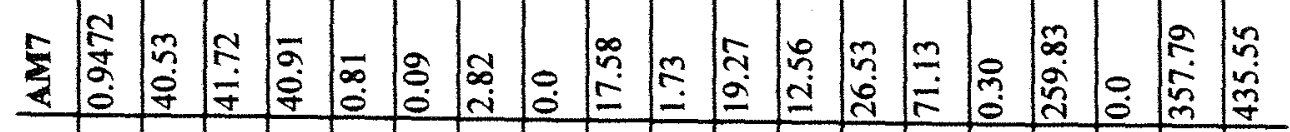

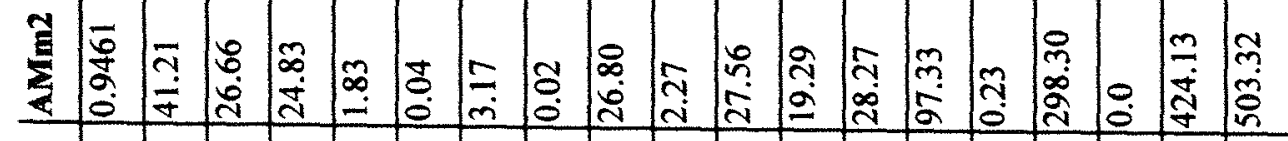

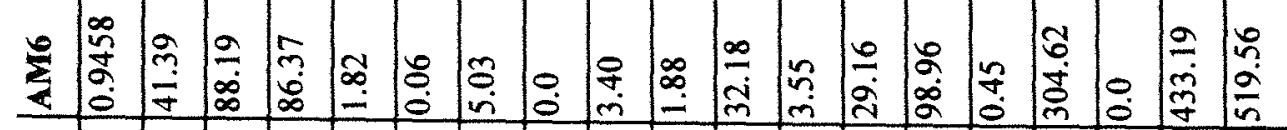

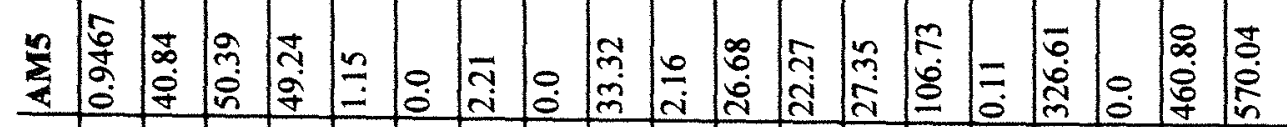

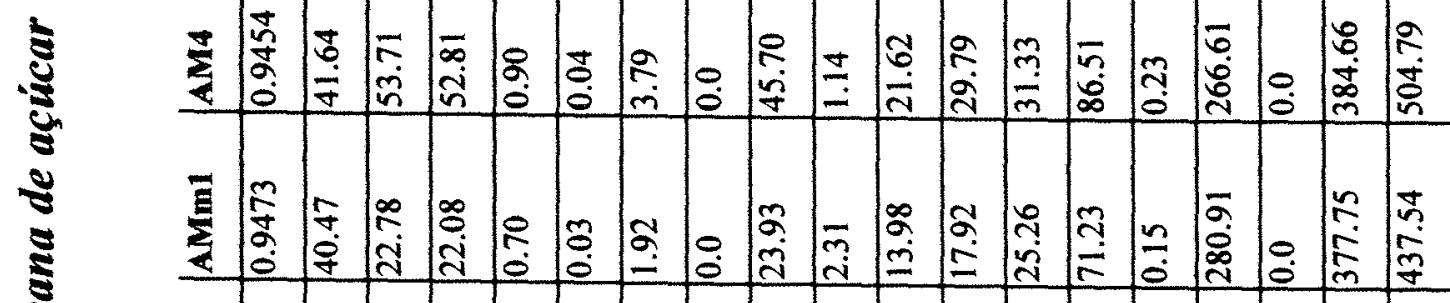

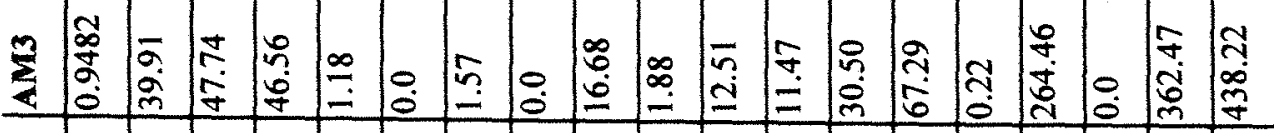

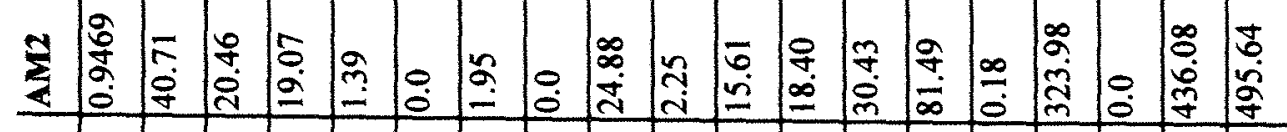

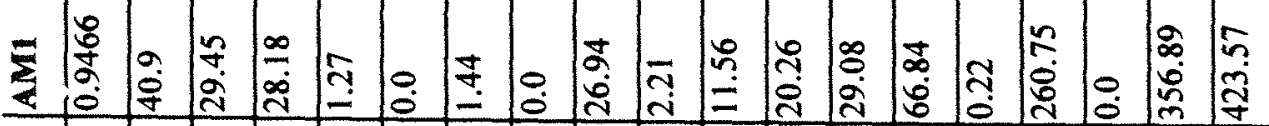

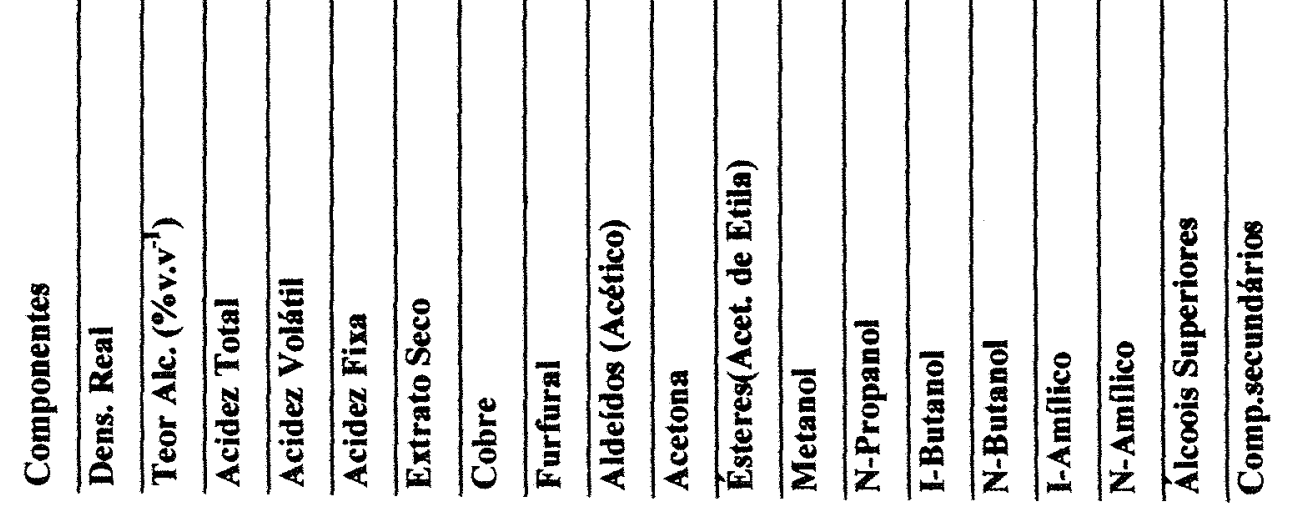

